\title{
\#USGS
}

science for a changing world

Prepared in cooperation with the Missouri River Recovery Program

\section{Development of Conceptual Ecological Models Linking Management of the Missouri River to Pallid Sturgeon Population Dynamics}

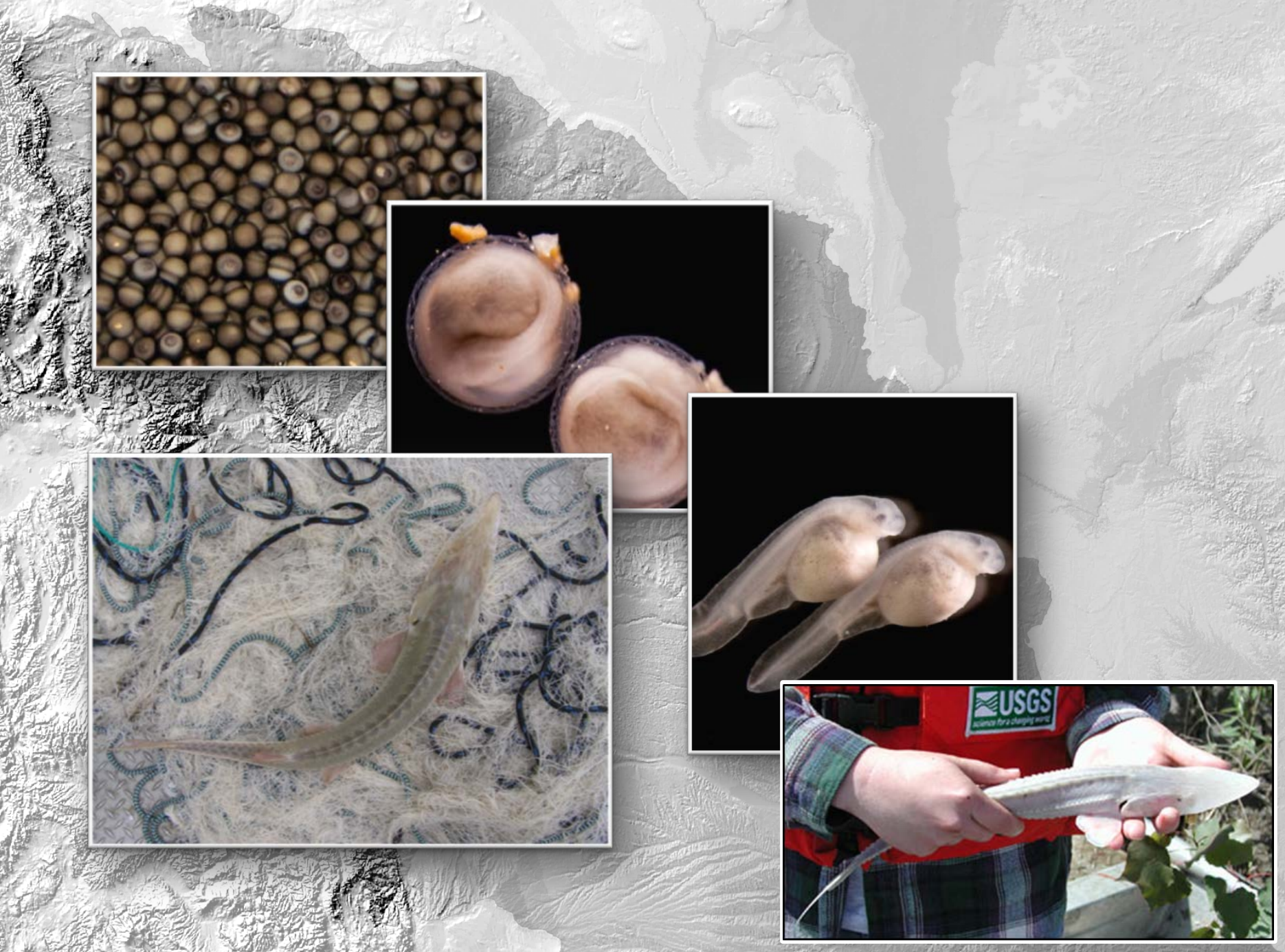

Open-File Report 2015-1038

U.S. Department of the Interior

U.S. Geological Survey 
Cover photograph index:

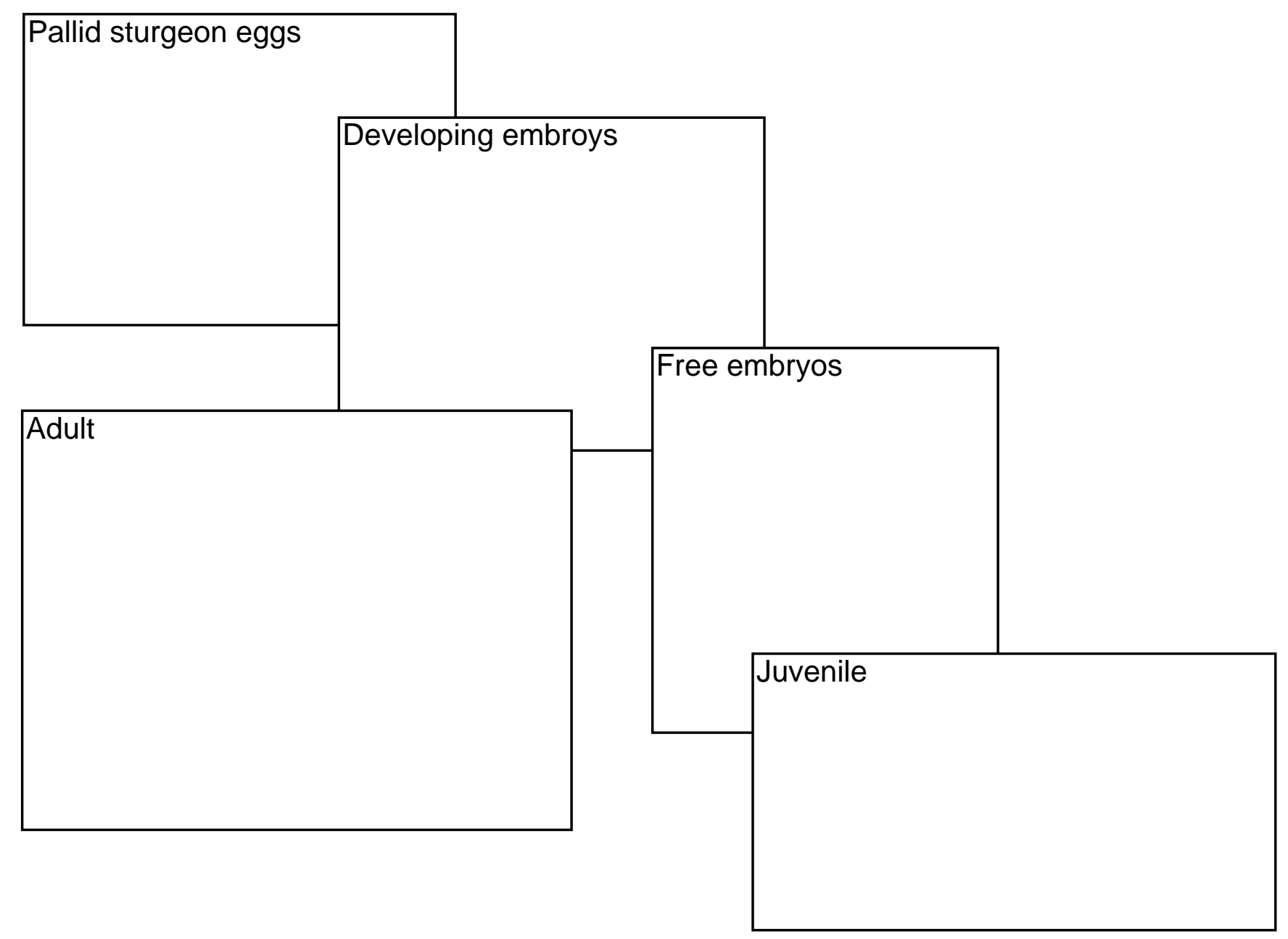

Background image: shaded relief map of the Missouri River drainage basin, US Geological Survey, EROS Data Center.

Photographs by U.S. Geological Survey personnel 


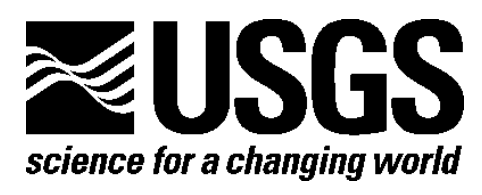

Prepared in cooperation with the Missouri River Recovery Program

\section{Development of Conceptual Ecological Models Linking Management of the Missouri River to Pallid Sturgeon Population Dynamics}

By Robert B. Jacobson, Michael J. Parsley, Mandy L. Annis, Michael E. Colvin, Timothy L. Welker, and Daniel A. James

Open File Report 2015-1038

U.S. Department of the Interior

U.S. Geological Survey 


\title{
U.S. Department of the Interior \\ SALLY JEWELL, Secretary
}

\author{
U.S. Geological Survey \\ Suzette M. Kimball, Acting Director
}

U.S. Geological Survey, Reston, Virginia 2015

For product and ordering information:

World Wide Web: http://www.usgs.gov/pubprod

Telephone: 1-888-ASK-USGS

For more information on the USGS-the Federal source for science about the Earth, its natural and living resources, natural hazards, and the environment:

World Wide Web: http://www.usgs.gov or Telephone: 1-888-ASK-USGS

Suggested citation:

Jacobson, R.B., Parsley, M.J., Annis, M.L., Colvin, M.E., Welker, T.L., and James, D.A., 2014, Development of conceptual ecological models linking management of the Missouri River to pallid sturgeon population dynamics: U.S. Geological Survey Open-File Report 2015-1038, 47 p., http://dx.doi.org/10.3133/ofr20151038.

Any use of trade, product, or firm names is for descriptive purposes only and does not imply endorsement by the U.S. Government.

Although this information product, for the most part, is in the public domain, it also may contain copyrighted materials as noted in the text. Permission to reproduce copyrighted items must be secured from the copyright owner.

ISSN 2331-1258 (online) 


\section{Acknowledgments}

The authors would like to thank participants in the collaborative conceptual ecological modeling workshops held during August, 2013. We are also grateful for conscientious reviews of this report by Clayton Ridenour, U.S. Fish and Wildlife Service, Columbia, Missouri, George Jordan, U.S. Fish and Wildlife Service, Billings, Montana, and Steve Chipps, South Dakota State University, and by members of the Missouri River Independent Science Advisory Panel. 


\section{Contents}

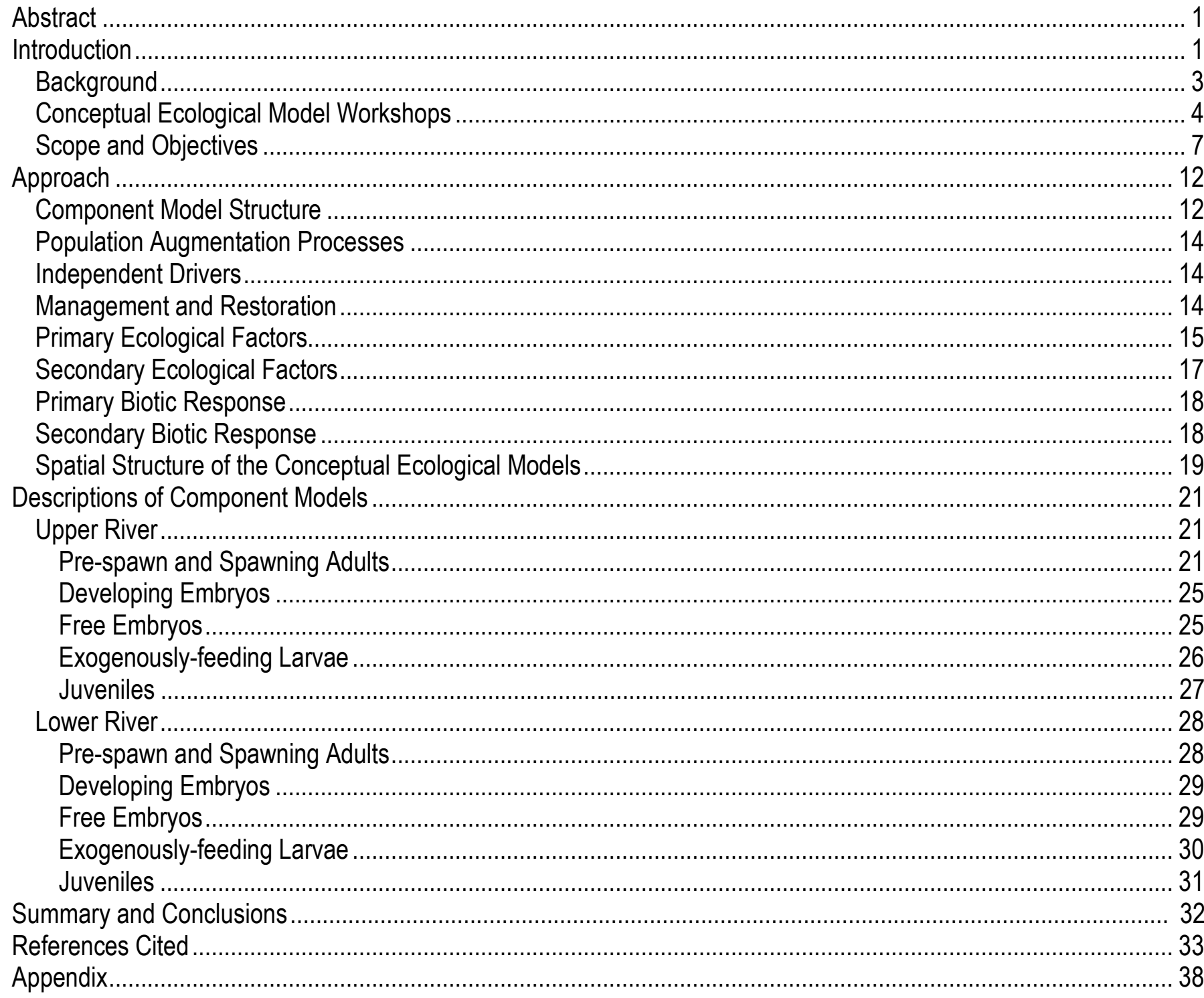

\section{Figures}

Figure 1. Process steps envisioned for the Missouri River Pallid Sturgeon Effects Analysis. .................................... 5

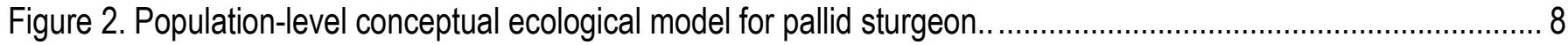

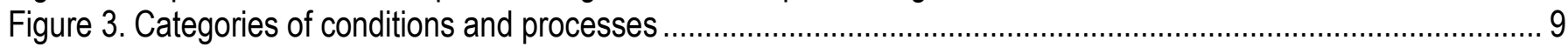

Figure 4. Arrangement of conditions and process affecting transition between two life stages. ................................ 9

Figure 5. Hierarchical arrangement of essential ecosystem characteristics applied to spring-rise managed flows on the Missouri River.

Figure 6. Pre-development and post-development range of pallid sturgeon in the Missouri and Mississippi river basins

Figure 7. Example of a component conceptual ecological model for pallid sturgeon effects analysis. 


\section{Tables}

Table 1. Descriptions of importance and uncertainty categories for CEMs ..................................................... 13

Table 2. Candidate working set of biologically dominant hypotheses. .......................................................... 22

\section{Conversion Factors}

International System of Units to Inch/Pound

\begin{tabular}{|c|c|c|}
\hline Multiply & By & To obtain \\
\hline \multicolumn{3}{|c|}{ Length } \\
\hline meter (m) & 3.281 & foot $(\mathrm{ft})$ \\
\hline kilometer $(\mathrm{km})$ & 0.6214 & mile (mi) \\
\hline \multicolumn{3}{|c|}{ Area } \\
\hline square meter $\left(\mathrm{m}^{2}\right)$ & 0.0002471 & acre \\
\hline hectare (ha) & 2.471 & acre \\
\hline hectare (ha) & 0.003861 & square mile $\left(\mathrm{mi}^{2}\right)$ \\
\hline \multicolumn{3}{|c|}{ Flow rate } \\
\hline meter per second $(\mathrm{m} / \mathrm{s})$ & 3.281 & foot per second (ft/s) \\
\hline
\end{tabular}

Inch/Pound to International System of Units

\begin{tabular}{lcl}
\multicolumn{1}{c}{ Multiply } & By & To obtain \\
\hline acres per mile & Density & hectares per kilometer \\
\hline
\end{tabular}

Temperature in degrees Celsius $\left({ }^{\circ} \mathrm{C}\right)$ may be converted to degrees Fahrenheit $\left({ }^{\circ} \mathrm{F}\right)$ as follows: -

${ }^{\circ} \mathrm{F}=\left(1.8 x^{\circ} \mathrm{C}\right)+32$ -

Temperature in degrees Fahrenheit $\left({ }^{\circ} \mathrm{F}\right)$ may be converted to degrees Celsius $\left({ }^{\circ} \mathrm{C}\right)$ as follows: -

${ }^{\circ} \mathrm{C}=\left({ }^{\circ} \mathrm{F}-32\right) / 1.8-$ 


\title{
Development of Conceptual Ecological Models Linking Management of the Missouri River to Pallid Sturgeon Population Dynamics
}

\author{
By Robert B. Jacobson, ${ }^{1}$ Michael J. Parsley, ${ }^{2}$ Mandy L. Annis,,${ }^{1}$ Michael E. Colvin, ${ }^{3}$ Timothy L. Welker,${ }^{4}$ and \\ Daniel James 5
}

\begin{abstract}
This report documents the process of developing and refining conceptual ecological models (CEMs) for linking river management to pallid sturgeon (Scaphirhynchus albus) population dynamics in the Missouri River. The refined CEMs are being used in the Missouri River Pallid Sturgeon Effects Analysis to organize, document, and formalize an understanding of pallid sturgeon population responses to past and future management alternatives. The general form of the CEMs, represented by a population-level model and component life-stage models, was determined in workshops held in the summer of 2013. Subsequently, the Missouri River Pallid Sturgeon Effects Analysis team designed a general hierarchical structure for the component models, refined the graphical structure, and reconciled variation among the components and between models developed for the upper river (Upper Missouri \& Yellowstone Rivers) and the lower river (Missouri River downstream from Gavins Point Dam). Importance scores attributed to the relations between primary biotic characteristics and survival were used to define a candidate set of working dominant hypotheses about pallid sturgeon population dynamics. These CEMs are intended to guide research and adaptive-management actions to benefit pallid sturgeon populations in the Missouri River.
\end{abstract}

\section{Introduction}

Conceptual models are used for a variety of purposes in resource management applications. A conceptual model is simply an abstract mental or graphical image of important parts of a system and how they are related. In an ecosystem context, conceptual models are defined as "graphic representations of interactions among key ecosystems components, processes, and drivers" (Woodward and others, 2008, p. 60). Conceptual models may vary broadly in their structure and complexity (Gentile and others, 2001); those created for ecological applications can get very complicated and often evolve into complex process-based (Walters and others, 2000) or probabilistic (Rieman and others, 2001; Stewart-Koster and others, 2010) computational models.

Conceptual models are frequently cited as a necessary step in formal adaptive management in which stakeholders and scientists jointly develop a shared understanding of what affects an ecosystem or population, and then apply the model to predictions of biological responses (hypotheses)

\footnotetext{
${ }^{1}$ U.S. Geological Survey

${ }^{2}$ U.S. Geological Survey

${ }^{3}$ Oregon State University

${ }^{4}$ U.S. Army Corps of Engineers

${ }^{5}$ U.S. Fish and Wildlife Service
} 
under management scenarios (Walters, 1986). The conceptual model also functions as a teaching and communication tool in the adaptive management process.

The purposes of the conceptual ecological models (CEMs) are presented in this report:

- to provide a broad perspective on factors potentially affecting the endangered pallid sturgeon (Scaphirhynchus albus) populations in the Missouri River;

- to serve as a communication tool about those factors and their possible linkages to management and restoration actions;

- $\quad$ to provide a structure from which priority hypotheses will be selected based on their importance in explaining pallid sturgeon population dynamics and their value in guiding Missouri River management decisions.

Priority hypotheses developed from the CEM components presented in this report will be used in a formalized effects analysis (Murphy and Weiland, 2011) to guide structured decision making in the Missouri River Recovery Program (MRRP). The Missouri River Pallid Sturgeon Effects Analysis (EA) is charged with a multistep process, resulting in four reports during phase 1 (fig. 1):

- develop CEMs to document and illustrate driver-stressor-response ecological relationships. The CEM development process is documented in the present report.

- develop a hierarchy of hypotheses to depict relations in the CEMs. The process of hypothesis formulation and filtering will be documented in the second report in the series and as a US Geological Survey Open-File Report

- compile and assess available information and modeling resources that can be used to understand historical and future changes of pallid sturgeon populations. This will be the third report in the series.

- compile an integrative, lines-of-evidence approach using best available science to assess hypotheses emanating from the hypothesis development process. This will include the best available combinations of qualitative and quantitative models, theoretical and empirical data, and expert opinion. This synthesis will be documented in an initial EA integrative report, that will be published as a U.S. Geological Survey Scientific Investigations Report.

These documents from the EA are intended to inform MRRP decisions about how to best manage the Missouri River and its resources to meet species objectives and authorized purposes. For pallid sturgeon in the Missouri River, the species objective is to "avoid jeopardizing the continued existence of the pallid sturgeon from US Army Corps of Engineers actions on the Missouri River." (U.S. Fish and Wildlife Service, unpub. data, 2013). The U.S. Fish and Wildlife Service (USFWS) notes that this objective is consistent with species recovery goals (U.S. Fish and Wildlife Service, 2014) but is specific to Missouri River management actions.

The CEM and quantitative model framework developed through the EA are intended to form part of the framework for future adaptive management in the Missouri River. Although drafting of the adaptive management plan is not currently (2014) complete, we anticipate that the plan will include an ongoing assessment process similar to the EA, whereby new learning from monitoring, assessment, and research efforts will be used to improve management actions with time. An important part of this effort will be the option to refer to the CEMs documented in this report if the need arises to provide new hypotheses to explain observed changes in pallid sturgeon populations.

The objective in developing the CEM is to provide a "global" set of process relations that may affect pallid sturgeon population dynamics. These hypotheses were developed through the expert opinion of sturgeon biologists and river scientists. The global set is a beginning point from which hypotheses can be progressively prioritized for quantitative simulation modeling based on their 
relevance in explaining pallid sturgeon population dynamics and their value in guiding decision making. These models will seek to predict survival probabilities at critical life stages as a function of management or restoration actions. The framework has been developed so the component models can be linked through a population model to provide a framework for assessing effects of management actions at the population level.

\section{Background}

The pallid sturgeon is an endangered, benthic fish endemic to the turbid Missouri and Mississippi Rivers and the lower parts of larger tributaries. The species was listed as endangered under the Endangered Species Act in 1990 (Federal Register, 1990) and in 2000 the USFWS published a biological opinion that indicated that U.S. Army Corps of Engineers (USACE) operations of the Missouri River were likely to jeopardize its existence. The primary stressors responsible were habitat alteration related to changes in flow regime and channel form among a long list of potential threats (Dryer and Sandvol, 1993). The biological opinion and a 2003 amendment defined elements of a reasonable and prudent alternative (RPA) to avoid jeopardy to these Missouri River populations (U.S. Fish and Wildlife Service, 2000, 2003). The pallid sturgeon RPA elements include (among others) implementation of adaptive management, monitoring, and research, restoration of 20-30 acres per mile $(5-7 \mathrm{ha} / \mathrm{km})$ of shallow-water habitat $(\mathrm{SWH})$, increased pallid sturgeon propagation and augmentation, and flow enhancements from Fort Peck and Gavins Point dams.

Large-scale restoration of Missouri River channel and floodplain habitats date from the Missouri River Bank Stabilization and Navigation Project Fish and Wildlife Mitigation Program (Mitigation Program), which was authorized in the Water Resources Development Act of 1986, 5 years after completion of the Bank Stabilization and Navigation Program (BSNP) (National Research Council, 2002). The Mitigation Program was intended originally to mitigate for habitat losses due to the BSNP, with a goal of restoring 166,750 acres of channel, sandbar, and meander belt habitat, approximately 32 percent of the estimated lost habitat (U. S. Army Corps of Engineers, 1981). The goals for compliance with the amended biological opinion and for the Mitigation Program were formally incorporated into the MRRP in the Water Resources Development Act of 2007 (WRDA 2007). The WRDA 2007 also authorized mitigation projects along the main stem Missouri River in the upstream segments of the river, including Montana, North Dakota, Nebraska, and South Dakota, as well as restoration projects in the Yellowstone River and its tributaries in Montana and South Dakota. The WRDA 2007 additionally authorized use of USACE funding to assist the Bureau of Reclamation with planning and construction of fish passage and entrainment protection at the Lower Yellowstone Project's Intake Diversion Dam (Intake Dam) and associated irrigation canal headworks.

Implementation of fish, wildlife, and habitat restoration activities on the Missouri River has been guided by principles of adaptive management since adoption of the 2000 "Missouri River Biological Opinion" (U.S. Fish and Wildlife Service, 2000) and the 2001 "Missouri River Mainstem System Master Water Control Manual" (U.S. Army Corps of Engineers, 2001). Adaptive management was adopted more formally with creation of the Missouri River Recovery Implementation Committee (MRRIC), an advisory group to the USACE authorized in the WRDA 2007, and committees or affiliates of MRRIC that are closely aligned with adaptive management: the Science and Adaptive Management (SAM) work group and the Independent Science Advisory Panel (ISAP). Emphasis on construction of CEMs and implementation of effects analyses were prominent recommendations of the ISAP to promote robust adaptive management of the Missouri River and its imperiled species (Doyle and others, 2011). 
Two levels of a conceptual model are presented here to apply to an understanding of ecological effects on pallid sturgeon populations. The population-level conceptual model is based on models documented in Wildhaber and others $(2007,2011)$. This model shows key components of a population model in which conditions and processes contribute to transition probability from one life stage to the next (fig. 2). In addition to identifying key life stages and life-stage transitions (survival probabilities), this population-level model shows the spatial dimension of habitat use by the pallid sturgeon. Because the pallid sturgeon can disperse or migrate for hundreds of kilometers in a season, different life stages play out in different parts of the river, generally with spawning habitat at the apex of upstream reproductive migrations and rearing habitat for larval and juvenile fish thought to occur substantially farther downstream as young fish disperse (Braaten and others, 2008; Braaten and others, 2012; DeLonay and others, in press).

The second level of CEM (the component model) addresses the conditions and processes affecting survival probabilities for each life stage. The component level was described in Wildhaber and others $(2007,2011)$ as linkages among processes. Processes included human-related direct mortality, non-human direct mortality (predation), rate-affecting factors (such as disease, habitat, prey availability, competition, and contaminants), and abiotic and biotic condition factors such as flow regime, sediment regime, temperature, and non-native and native fishes (fig. 3). Combinations of processes and conditions thought to be most important were shown as interactions that affected survival probabilities for each life-stage transition (fig. 4).

Another CEM for pallid sturgeon was developed for application to Missouri River restoration activities with emphasis on hierarchical propagation of management actions through essential ecosystem characteristics (EECs) of abiotic effects, habitat effects, and biotic responses (Jacobson and Berkley, 2011). Jacobson and Berkley (2011) showed a specific application to assessment of how flow modifications may affect pallid sturgeon reproductive ecology (fig. 5). Jacobson and Berkley (2011) also demonstrated how the hierarchical approach could be useful in understanding causal linkages and applied to allocation of monitoring and assessment resources. A similar hierarchical approach to conceptual ecological modeling was suggested by the Missouri River ISAP for application in understanding species recovery (Doyle and others, 2011).

\section{Conceptual Ecological Model Workshops}

The conceptual models discussed in this report arose from a series of workshops hosted by the USACE and USFWS in 2013 under the auspices of the USACE Missouri River Recovery Program (MRRP). Workshop participants were sturgeon biologists, landscape ecologists, and river experts from State and Federal agencies. Workshop goals were to review and refine CEMs and to develop objectives to be used during the planning and adaptive management process for the pallid sturgeon. Because of substantive difference in management issues, separate workshops were convened for the lower river and the upper river (fig. 6). The lower river group met July 17 and 18 and the upper river group met July 23 and 24.

During the lower river workshop, the attendees adopted a graphical format in which hierarchical component-level models feed into individual life-stage survival probabilities. This general structure was thought to lead effectively into a stage-based population model and was therefore adopted as the eventual end point of the conceptual modeling process. These ideas were subsequently accepted by the upper river workshop attendees. 

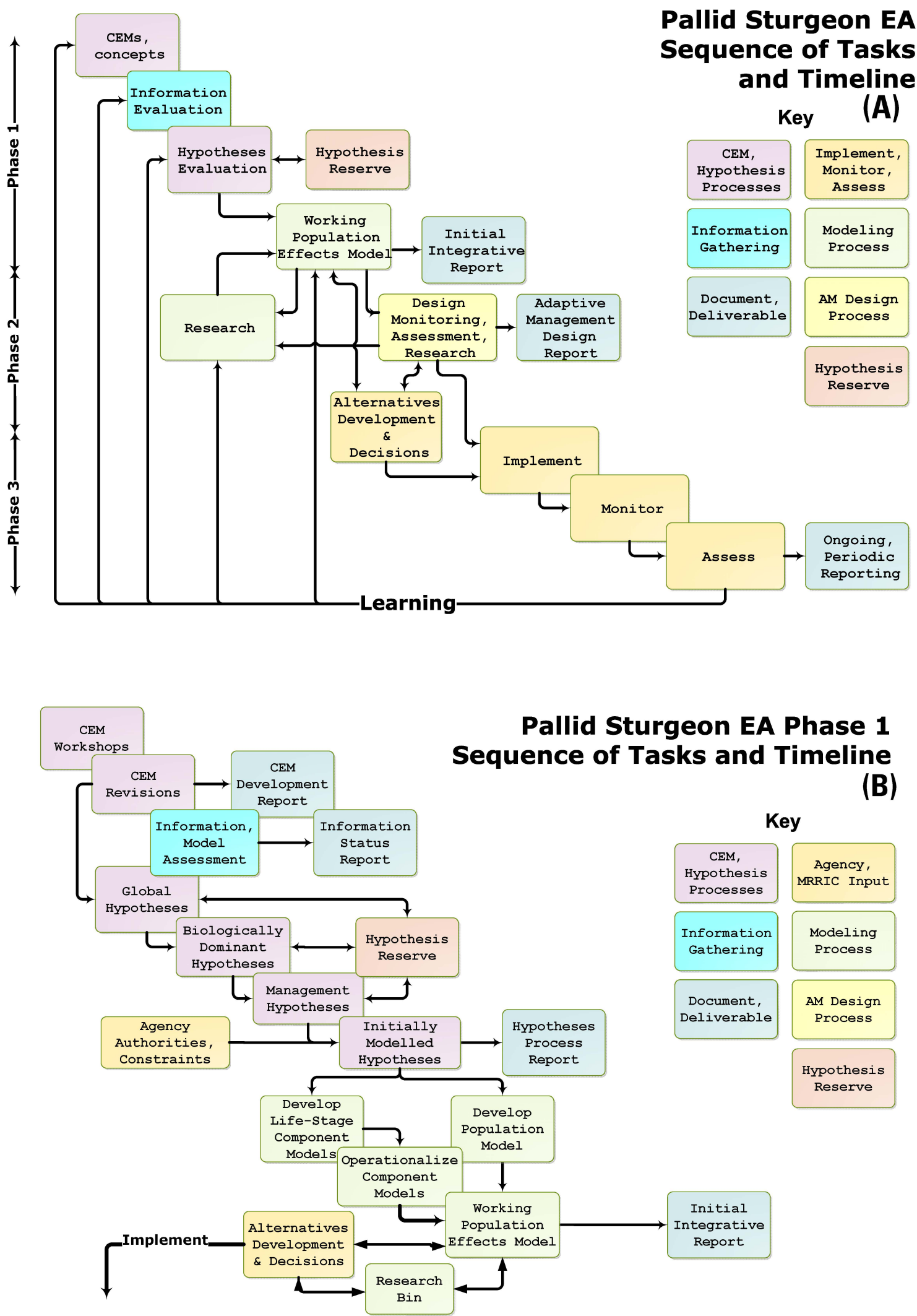

Figure 1. Process steps envisioned for the Missouri River Pallid Sturgeon Effects Analysis. A, Broad-scale view of the EA role in the ongoing process of assimilation and evaluation of information developed through adaptive management of the Missouri River. B, Detail of steps in phase 1 of the EA. The present report is the CEM Development Report. Subsequent steps assess available science information, document hypothesis filtering, and synthesize a lines-of-evidence approach to evaluating management effects in pallid sturgeon populations. 
The original guidance for the workshops included geographic scope and some working assumptions. As the workshops progressed, some of these assumptions were relaxed or revised, as indicated by determinations listed below:

- Guidance.- The geographic scope is the Missouri River from Fort Peck downstream to the confluence of the Mississippi River and includes specific elements of the Biological Opinion as amended, like the Intake Diversion Dam Project on the Yellowstone River.

o Determination.- During the workshops, it was determined that the reservoir and inter-reservoir reaches from the headwaters of Lake Sakakawea (not shown) to Gavins Point Dam would not be considered explicitly in this phase of conceptual ecological modeling. The potential for inter-reservoir reaches with clear, cold water and hydropeaking releases to contribute to pallid sturgeon recovery was considered low but may be usefully considered in a subsequent phase of analysis

o Determination.- It was also determined that processes and conditions acting in Missouri River tributaries and the Mississippi River should be included in the CEMs if those processes and conditions would affect population processes in the target geographic area.

- Guidance.- Conceptual ecological model and objectives are focused on MRRP responsibility to avoid jeopardy to listed species.

o Determination.- During the workshops, it was determined that the CEMs should be more broadly constructed so as to consider a wide range of conditions and processes beyond those that are the responsibility of the MRRP. This decision was based on the understanding that the CEMs should be illustrative of the universe of hypotheses determining pallid sturgeon population dynamics to provide explanation for instances in which MRRP actions to avoid jeopardy are unsuccessful because of conditions and processes outside of MRRP control.

- Guidance.- The drivers identified in the species CEMs will be limited to the USACE management actions that have an effect on species performance.

o Determination.- Similar to the logic articulated in the previous bullet, the workshop participants believed that the CEMs should be more broadly constructed so as to consider all conditions and processes, even those that are not the responsibility of the MRRP. It is anticipated that during subsequent steps in the effects analysis process, priority hypotheses will be identified based on their relevance to pallid sturgeon population dynamics and their importance to decision making under the MRRP.

- Guidance.- The RPA elements included in the CEMs will be limited to those included within the 2003 "Missouri River Biological Opinion" (U.S. Fish and Wildlife Service, 2003). Our aim is not to develop models that include "everything" that may affect the species. Rather, the models should be focused on those issues relevant to decision making for the MRRP. The models developed in these workshops are intended to illustrate the effects of USACE operations and restoration actions on the listed species; therefore, the models should have a bias toward management actions and how they propagate through the ecosystem.

o Determination.- The workshop participants believed that some relevant management actions may not have been envisioned when the 2003 "Missouri River Biological Opinion" (U.S. Fish and Wildlife Service, 2003) was drafted, and the CEM process was a useful venue for developing and evaluating new potential actions that might be feasible under various existing authorities.

At the end of the workshops, smaller teams were assigned to clarify the graphic models and to populate spreadsheets that were designed to describe every box and arrow in the graphic models; 
this phase of model revision was completed by September 15, 2013. The draft models were provided to interested stakeholders and members of the public for technical review during a 30-day review period ending on October 30, 2013. The review comments were compiled by the MRRP, and the comments, model materials, and workshop notes were supplied to the members of the Missouri River Pallid Sturgeon EA team (the authors of this report) in preparation for the next phase of refinement.

\section{Purpose and Scope}

This report is the first in a series intended to document the Missouri River Pallid Sturgeon EA process (fig. 1). In this report, we present and describe refined global, component CEMs for pallid sturgeon in the Missouri River. The models are described as "global" to denote that they include a large number of potential relations among conditions and processes, each of which can be considered a hypothesis or part of a hypothesis. It is acknowledged that some relations may be highly uncertain, some may be considered to have small probability of increasing survival and population growth, and some may be tenuously linked to management actions under the MRRP. Nevertheless, the universe of potential processes is considered important to encourage critical thinking about pallid sturgeon population dynamics and to set the stage for subsequent refinement and prioritization of hypotheses for simulation modeling.

The individual life-stage models are described as "component" to denote that they apply to conditions and processes that determine discrete life-stage survival probabilities. The component models are linked conceptually and computationally through the stage-based population-level model (fig. 2), which, if properly structured and parameterized, will be useful in simulating population dynamics responses to management actions. The EA team has determined that hypotheses that address population augmentation (stocking) fit best within the population-level model.

This report documents the approach used to refine the component conceptual models resulting from the workshops and provides a narrative describing key relations among ongoing, proposed, and potential future management actions and ecological factors that alter survival probabilities. The objective of this report is to present component CEMs that clearly, logically, and systematically illustrate the current understanding of the universe of conditions and processes that may affect pallid sturgeon population dynamics in the Missouri River. Although we have revised the models that came out of the workshops in an attempt to achieve a uniform format, we have maintained as much of the structure and priorities of the original workshop products as possible. The intent is for these models to act as a robust foundation for subsequent prioritization of hypotheses and construction of simulation models; however, it is also expected that the models will be revised continually as learning is updated through an adaptive management process that includes robust research, monitoring, assessment, and learning (fig. 1).

The CEMs are considered the first step in a process to prioritize and focus on essential models needed to inform management decisions faced by the MRRP. The fundamental objective is to inform decisions that will avoid and prevent jeopardy for the pallid sturgeon in the Missouri River (unpub. data, 2013). Eventually, CEM graphics and descriptions will be refined into a set of working dominant hypotheses that represent a scientific perspective on factors that plausibly contribute to population decline of the pallid sturgeon in the Missouri River. These hypotheses may be similar to threats listed under the pallid sturgeon recovery plan (U.S. Fish and Wildlife Service, 2014) but will be more geographically focused on the Missouri River. A subsequent step will develop hypotheses for the multiple pathways from management actions that may lead to increase in survival or decrease in mortality at each life stage; these will be referred to as working management hypotheses. 


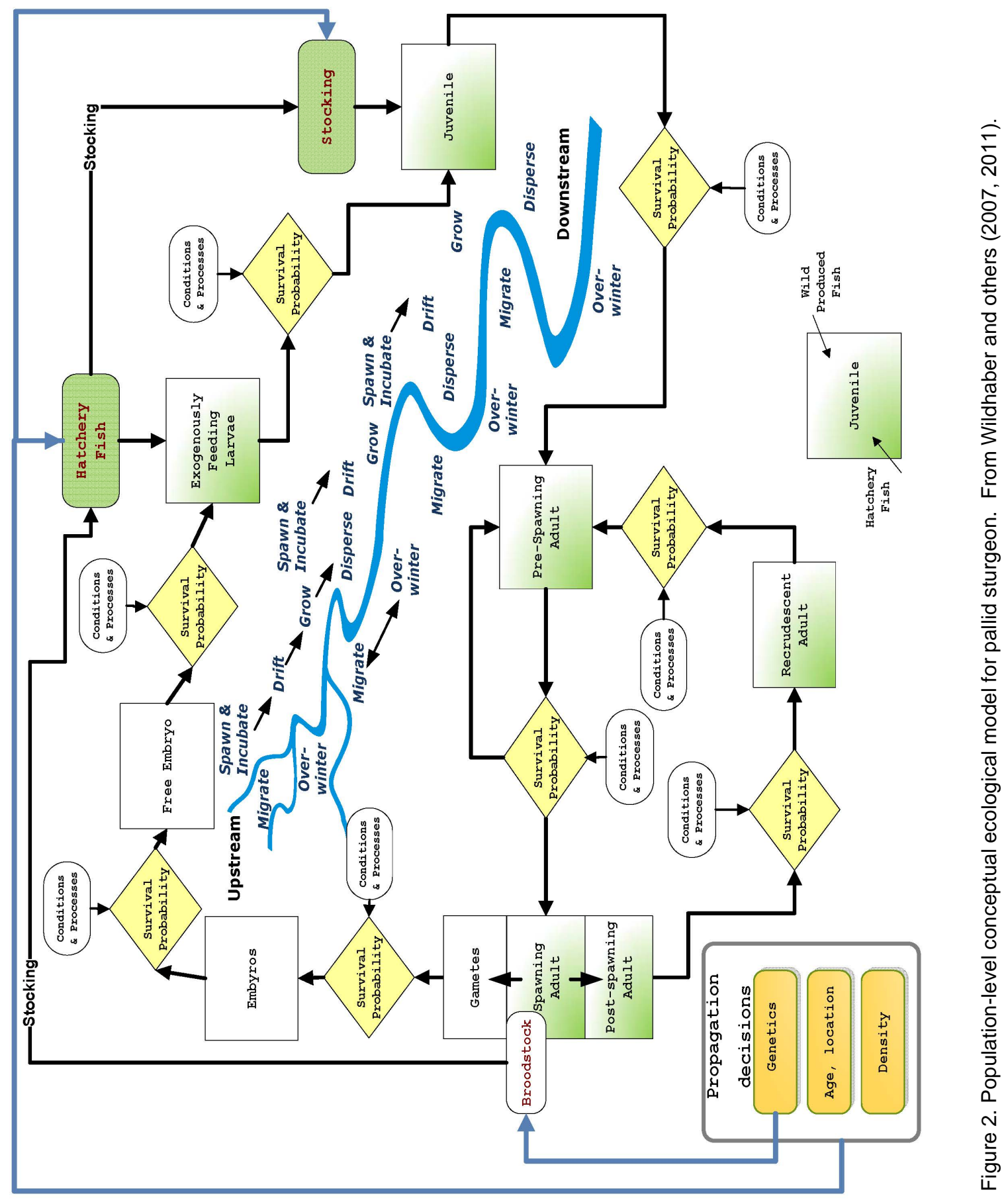



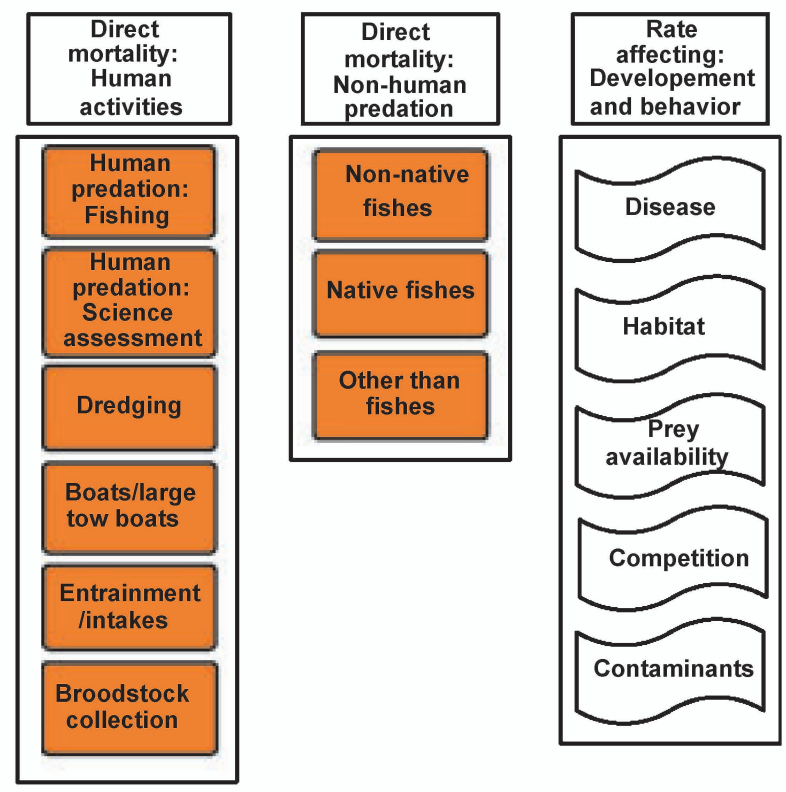

\section{Condition factors}

and behavior

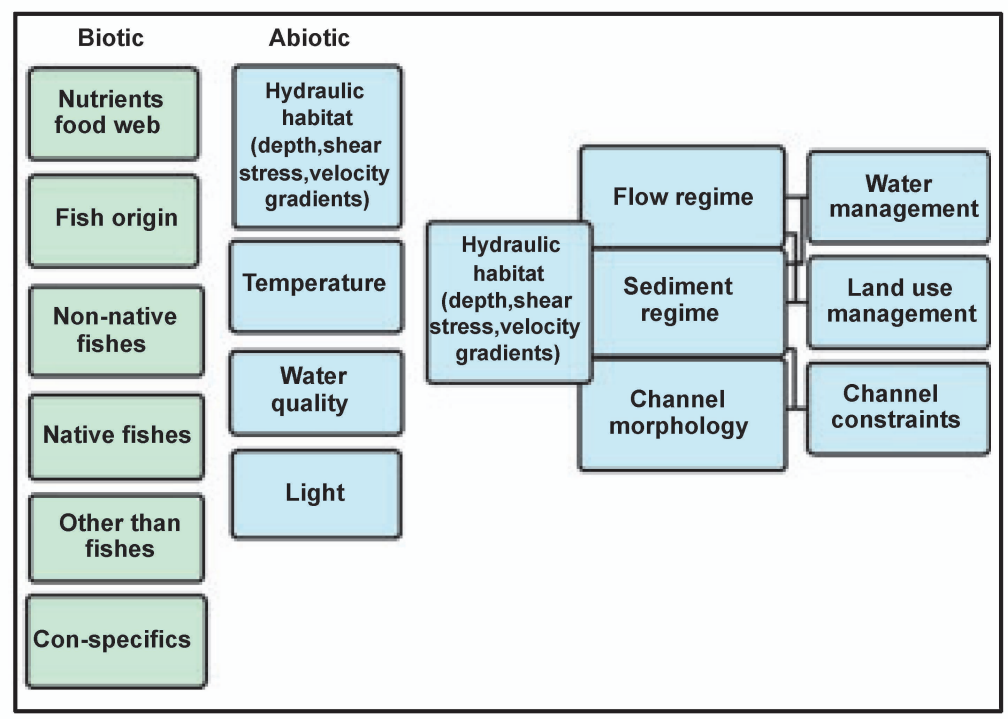

Figure 3. Categories of conditions and processes (Wildhaber and others, 2011).

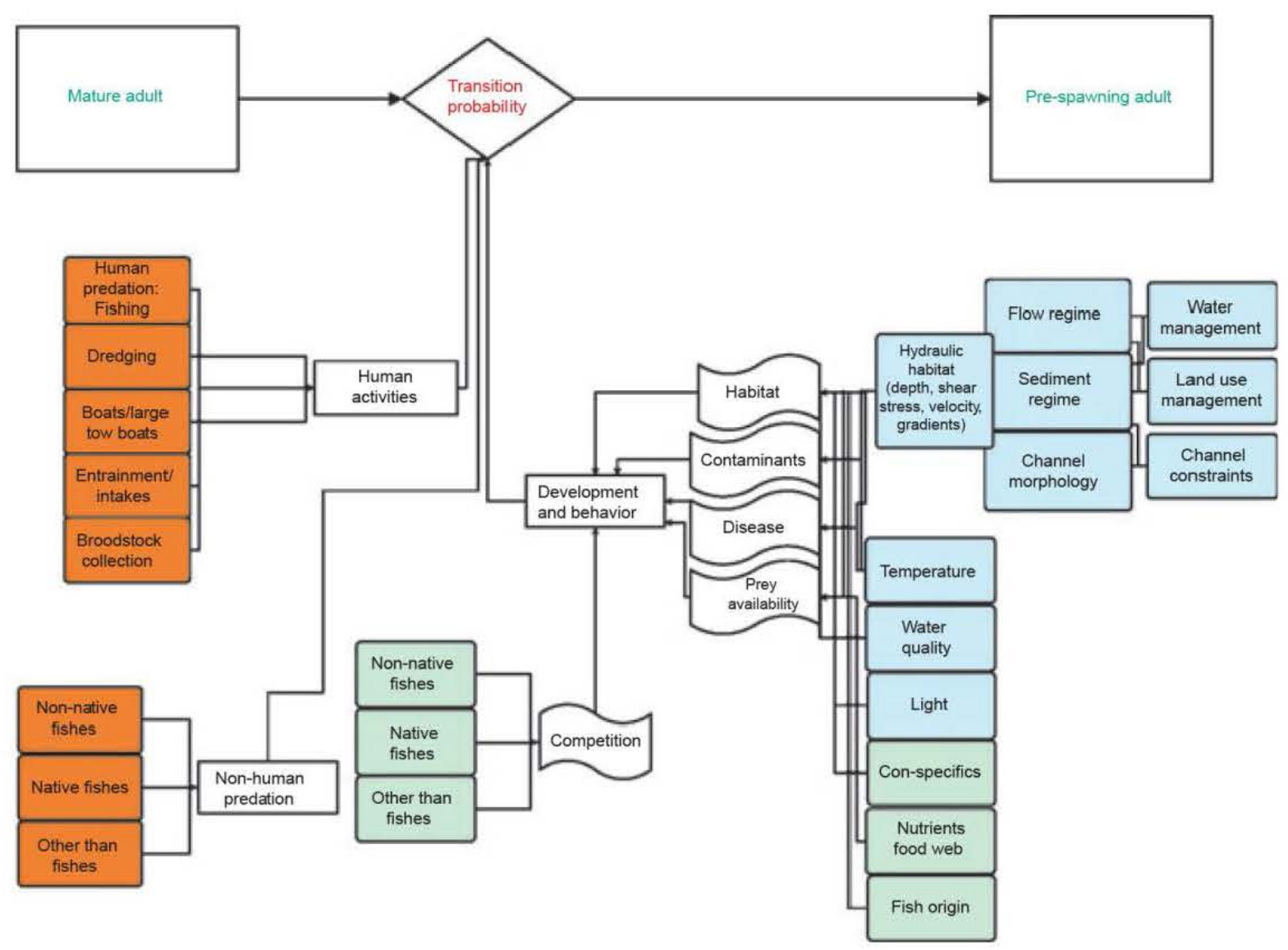

Figure 4. Arrangement of conditions and process affecting transition between two life stages (Wildhaber and others, 2011). 


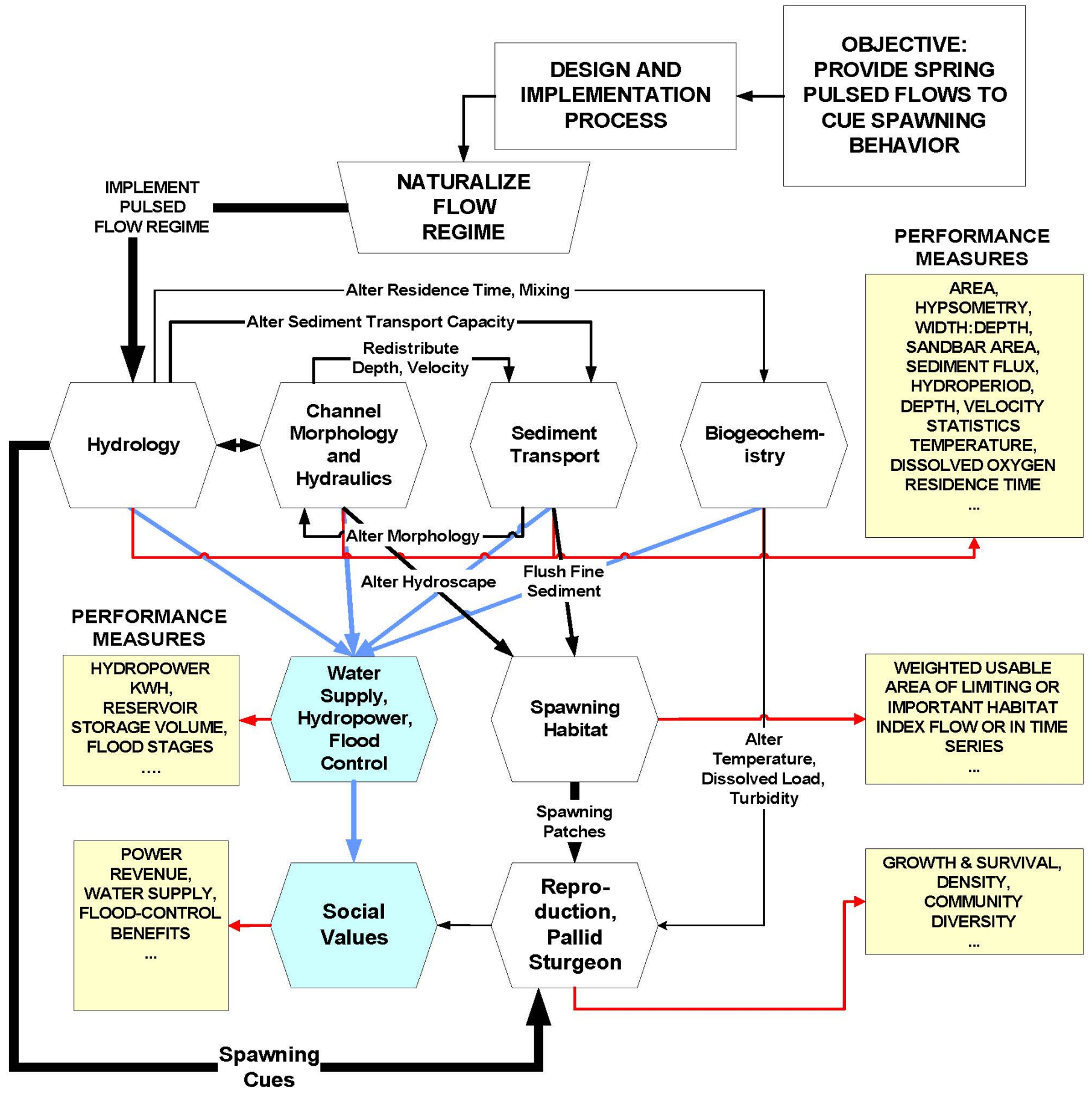

Figure 5. Hierarchical arrangement of essential ecosystem characteristics applied to spring-rise managed flows on the Missouri River (Jacobson and Berkley, 2011). 

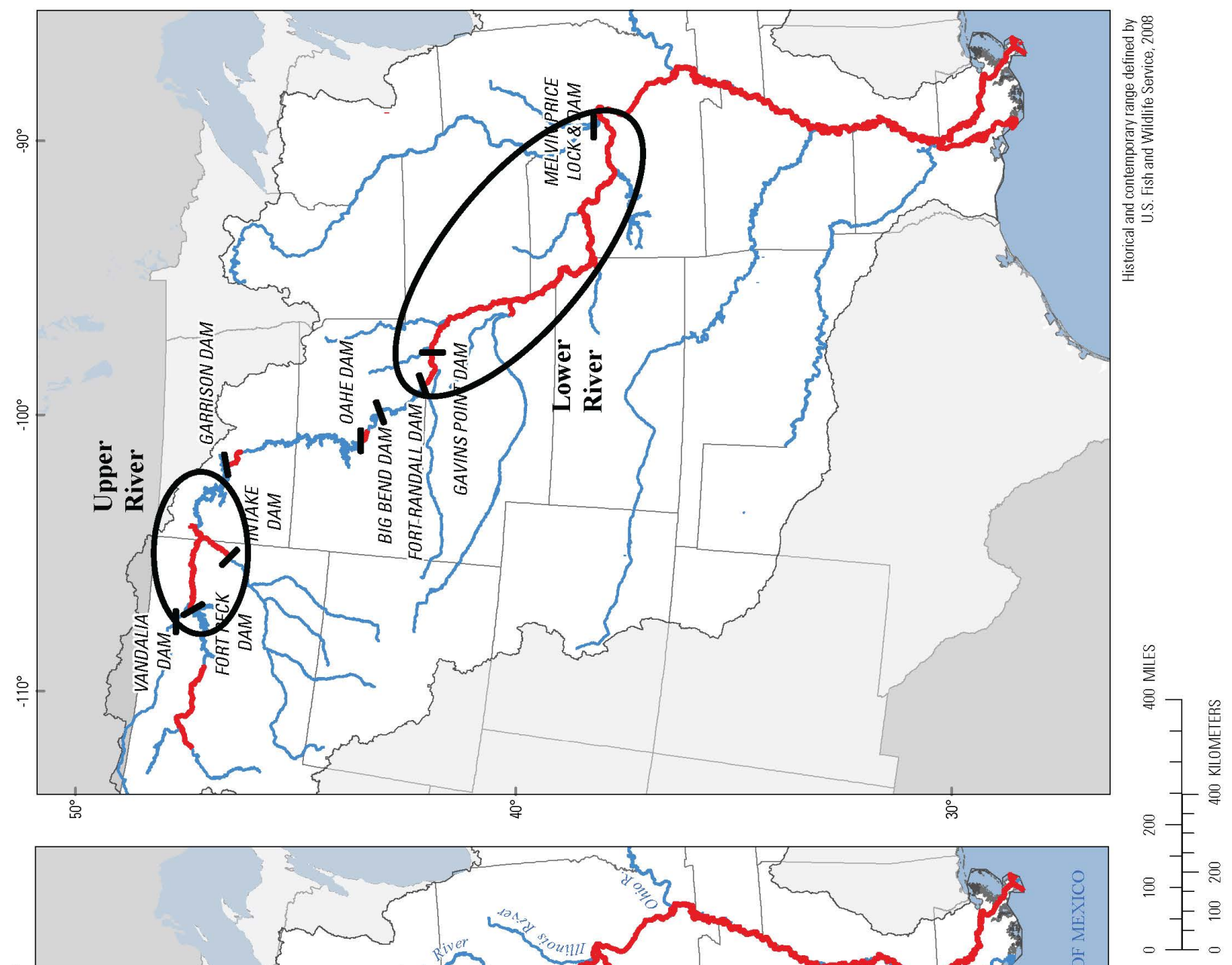

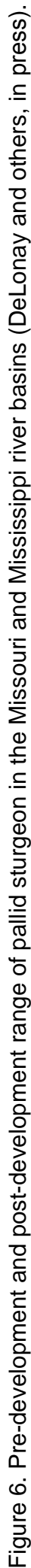


Management hypotheses will consider actions that could logically be accomplished to aid species recovery without testing for whether they fall within USACE authorities. The management hypotheses will also be more spatially explicit because some management options will be more effective in certain areas. Management hypotheses will also have similarities to recovery tasks in the pallid sturgeon recovery plan (U.S. Fish and Wildlife Service, 2014) but will address the fundamental objective of removing and precluding jeopardy, rather than specifically recovering the species.

The final step in the prioritization process will involve filtering the management hypotheses for those that fall within USACE authorities and jurisdictions. This set of initially modeled hypotheses will guide near-term modeling by the EA team to apply to management decisions. Identification of the bounds of actionable hypotheses will be the joint responsibility of USACE and USFWS.

\section{Approach}

The component CEMs are designed in a hierarchical, left-to-right structure, culminating in a survival probability. The survival probabilities correspond to the survival probabilities in the population-level model (fig. 2), such that processes and conditions in the component models are linked to survival from one life stage to the next. In this manner, the effects of specific management actions can be propagated through the component models to alter survival probabilities, with consequent effects on population dynamics. The overall structure is that of a stage-based populationlevel model and corresponds to the general concept of application of population viability analysis in effects analysis discussed by Murphy and Weiland (2011). Published work on pallid sturgeon populations and models provides understanding of population dynamics under current (2014) conditions (Bajer and Wildhaber, 2007; Steffensen and others, 2013a, 2013b), and an initial structure for incorporation of future management and ecological effects.

Separation of management actions, conditions, and processes by life stage is critical for the pallid sturgeon because historical alterations, engineering features, and life-stage processes vary spatially and temporally within the sturgeon's home range (the total length of river used by the pallid sturgeon during its life). Because survival probabilities vary considerably by life stage, the differential survival probabilities may be important in prioritizing management actions. Indeed, workshop participants determined that present knowledge of survival probabilities indicates that only five of eight life-stage transitions shown in figure 2 were relevant to understanding present-day population dynamics and would be considered in the component CEMs. The assumed value of a stage-based model (compared to an age-based model) is that transitions from one stage to another are thought to be biologically important and likely associated with abruptly increased or decreased chances of mortality. Developmental stages can be problematic to define, however, especially if transitions between them are not abrupt, such as the transition from exogenously feeding larvae to juveniles. Moreover, developmental stages do not have a 1:1 relation with ages or with sampling gears, especially at early life stages. Therefore, although the stages selected for these CEMs may provide biological insights, they may need to be modified in the future to conform to fish sampling datasets or modeling needs, or they may need to be supplemented to accommodate new insights into pallid sturgeon biology.

\section{Component Model Structure}

The component models are arranged hierarchically in a modification of a driver-stressor format (fig.7). In recognition that the ultimate drivers of river-system change are anthropogenic or geologic/climatic, only factors in the far left column are considered to be independent drivers. Each pair of columns, from left to right, can be considered a driver-stressor pair, with the final column being 
the ultimate biotic response (secondary biotic response, or change in survival probability). The columns categorize the hierarchy of factors into management and restoration, primary ecological factors, secondary ecological factors, and primary biotic responses. The columns are similar to tiers of EECs developed to provide hierarchical organization in other CEMs (Harwell and others, 1999; Lubinski and Barko, 2003; Jacobson and Berkley, 2011). An important feature of the columns (and tiers of EECs) is that uncertainty in predictions and biological relevance generally increases to the right, moving from abiotic time series to habitat (availability of biological important physical spaces in time and space) to biotic responses (growth, reproduction, survival). A critical question faced by many adaptive management programs is how to allocate resources to predictive modeling, monitoring, and assessment among the columns to provide the most cost effective information for decision making (Jacobson and Berkley, 2011).

The refined CEM diagrams include nested boxes allowing for additional levels of hierarchical organization within each column. The bounding boxes are broad descriptions of ecosystem factors and are common to all component models. The colored boxes within the bounding boxes are more specific factors; these factors vary by component model to emphasize that different factors are thought to be important in different locations and at different life stages. The nested structure provides additional flexibility for depicting relations among factors because the linking arrows can be attached to either the bounding boxes or to the specific boxes depending on how modeling needs and (or) available information dictate that the relations should be lumped or split.

Arrows indicate linkages among factors and are depicted by nine different combinations of colors and patterns based on workshop participants' understanding of relative uncertainty and importance to population dynamics. Although many more potential linkages could have been constructed, the linkages shown in the diagrams present those which workshop participants considered to have at least a small, modifying effect. Assignments to uncertainty and importance categories occurred during the modeling workshop and have been maintained with few revisions for the versions presented here. Relative importance is symbolized as a progression from dotted to dashed to solid lines, reflecting low to high importance. Relative uncertainty is symbolized as a progression from black to red, reflecting low to high uncertainty. A qualitative description of the categories is shown in table 1. Assignment to uncertainty and importance categories is expected to change as the models go through subsequent phases of review and revision, and as additional information becomes available.

Table 1. Descriptions of importance and uncertainty categories for conceptual ecological models.

\begin{tabular}{lll}
\hline Type & Label & Description \\
\hline Importance & High & $\begin{array}{l}\text { A link that is known or thought to have a direct and substantive } \\
\text { effect in altering another condition or process. } \\
\text { A link that is known or thought to have an indirect, modifying effect } \\
\text { another condition or process. } \\
\text { A link that is known or thought to have a small modifying effect on } \\
\text { another condition or process. }\end{array}$ \\
& Low & $\begin{array}{l}\text { A link with no published literature to support understanding. } \\
\text { A link with some support from published studies on other species or } \\
\text { rivers. } \\
\text { Ancertainty }\end{array}$ \\
& High & $\begin{array}{l}\text { A link supported by information from peer-reviewed studies specific } \\
\text { to the question and species. }\end{array}$ \\
\hline
\end{tabular}




\section{Population Augmentation Processes}

An additional CEM component is designed specifically to describe population augmentation through propagation. As represented in the population model (fig. 2), propagation occurs as temporary or permanent removal of broodstock from the adult population and as stocking of hatchery-reared fish in exogenously feeding larvae and juvenile stages (mostly as juveniles). The conditions and processes that influence how propagation takes place are information based rather than ecological. That is, propagation management decisions are made based on information on relative survival of different age classes, relative survival in different parts of the river, and parental genetics as they relate to understanding of the natural, underlying genetic composition of the population. These decisions are represented on the diagram for the population-level model (fig. 2).

It is possible that wild-produced and hatchery-produced fish will respond in different ways to the same environmental factors, resulting in differential survival probabilities. Hatchery fish may be poorly acclimated to natural conditions, may have difficulty adapting to natural food sources, may lack imprinting to water quality and habitat conditions, or may harbor disease in greater proportion than the natural environment. Therefore, the population-level conceptual model provides capability for tracking hatchery fish separately from wild-produced fish, which is illustrated in the population-level model (fig. 2) by the dual-color of the boxes representing numbers of wild and hatchery individuals in each life stage. Although hatchery and wild-produced fish are not depicted in the presentation of the component models, implementation of dual tracking in the population model may also require duplicate component models to capture the differential survival between them.

\section{Independent Drivers}

Independent drivers are categorized into (1) social, political, and economic drivers of change; and (2) physical factors (climate, geology, land use, and non-USACE management and engineering) that control fluxes of water, energy, sediment, and chemical constituents into the system or present hard geologic or engineered constraints to river processes. The two categories are related, but the relation is asymmetric. Physical factors clearly influence social, political, and economic drivers of change by determining biophysical capacity of the Missouri River, or, for example, imposing extreme events such as floods and droughts. Because of the complexity of decision making at the scale of the Missouri River, the linkage is symbolized as highly important but uncertain. Social, political, and economic drivers of change affect physical factors mainly through land-use change and non-USACE management activities. Examples might be basin-scale changes in agricultural production as a result of biofuels technology or international demand for commodities, or construction of reservoirs or channel stabilization projects outside of USACE MRRP authorities. These factors are symbolized as moderate importance and highly uncertain to reflect the judgment that social, political, and economic actions sufficient to change physical factors in the Missouri River basin are likely to be small relative to the effects of the existing main stem reservoirs and channel engineering. Moreover, the effects of these drivers are uncertain because of difficulties predicting the net effects of decentralized actions in the basin. The independent drivers are identical for all 10 component models although the nature of their linkages to other factors varies geographically.

\section{Management and Restoration}

There are many linkages from independent drivers to the column of factors labeled "Management and Restoration" in figure 7. For the purposes of these CEMs, management and restoration actions relate specifically to the USACE management actions, with the actions of other agencies represented as drivers. This structure follows the substantive effect that USACE management and restoration actions have on the main stem Missouri River and from the intent to 
apply these models in the near term to MRRP decision making. The management and restoration factors modify inputs from the physical and the social, political, and economic drivers. This conceptualization of how management and restoration actions work in the Missouri River system emphasizes their limits. A specific example is the limit of the reservoir system to filter basin-wide floods and droughts; the reservoir system acts as a filter that modifies magnitude, frequency, duration, timing, and rate of change but is not adequate to completely counteract climatic extremes imposed on it (Jacobson and Berkley, 2011). Some linkages bypass the management and restoration column, indicating those management decisions or conditions propagate to the river but are not affected, or are minimally affected, by USACE projects. An example would be potential water contamination by urban wastewater discharges or agricultural runoff.

Management and restoration factors have been subdivided into two bounding boxes indicating the two broad categories of management actions under USACE authorities. The first collects factors related to channel management and restoration, including channel configurations (channelization and channel-training structures) and bank stabilization. Channel reconfigurations include changes to channel geometry to result in increased complexity and habitat provision while maintaining an acceptable level of authorized purposes. Bank stabilization was given a separate category because some stabilization activities in the Upper and Lower Missouri Rivers are independent of the BSNP. The second bounding box includes factors related to the main stem reservoir system, including operating rules, fish-passage structures, water-quality structures, and locations. The factors represent possible actions that might be applied to operations of the main stem reservoir system even if present-day engineering does not accommodate them. For example, fish-passage and water-quality structures (structures or processes to vary temperature, dissolved oxygen, and (or) sediment concentrations in releases) were never designed for the main stem dams but could possibly be installed. The category of passage structures includes potential fish-passage designs for the Intake Dam on the Lower Yellowstone River. Locations refer to present or future locations of dams on the main stem system. The locations category has specific application to consideration of how dam locations operate to impede migrations, dispersal, and survival of pallid sturgeon, and how those locations interact with the natural genetic structure of the pallid sturgeon metapopulation.

The management and restoration factors are identical for all 10 component models although the importance and uncertainty of linkages vary considerably. A large difference among component models is the high importance and certainty ascribed to channel configuration and bank stabilization on the Lower Missouri River, and the relative low importance of channel engineering on the Upper Missouri River. Another substantive difference is the relatively long section of channel in the lower river that integrates large variation in climate, geology, and land use from large tributaries to affect sediment regime, water-quality regime, and flow regime. The Lower Missouri River also allows for extremely long, potential migration and drift distances, as much as 2,000 miles, by connection with the Mississippi River. In contrast, the upper river is fragmented into a 220-mile segment of the Upper Missouri River and a 234-mile segment of the Yellowstone River.

\section{Primary Ecological Factors}

Primary ecological factors are abiotic physical and chemical characteristics of the river ecosystem. Three of them are described as regimes (that is, time series of fluxes or concentrations that can be described in terms of magnitude, frequency, duration, timing, and rate of change). The flow regime frequently receives the most interest in river management and restoration because it has been described as the master variable for aquatic riverine ecosystems under the assumption that 


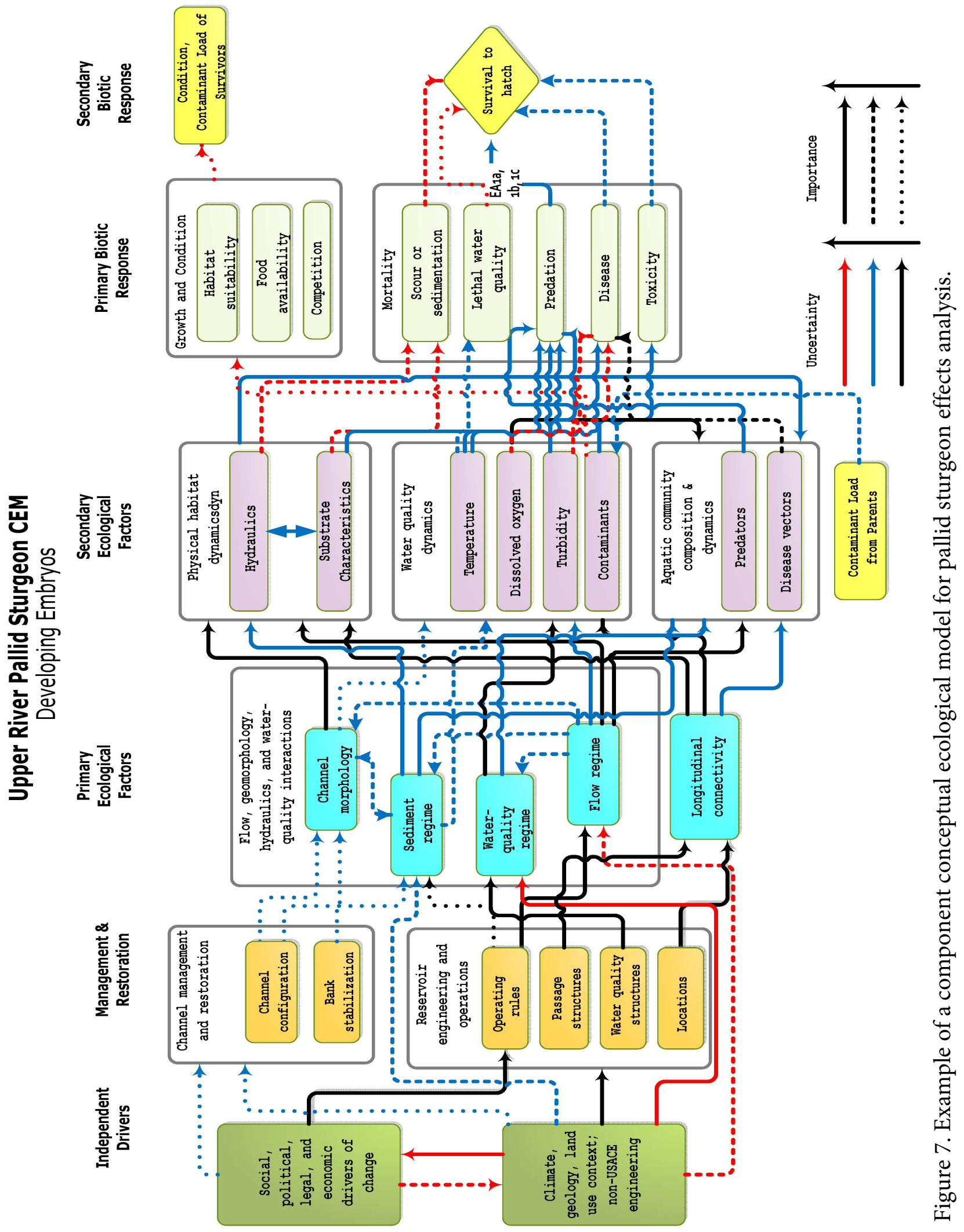


other characteristics of aquatic ecosystems, including sediment regime, water-quality regime, and channel morphology, adjust in response (Poff and others, 1997). In highly engineered river systems, however, the flow regime is typically decoupled from sediment, water quality, and channel morphology (Jacobson and Galat, 2006, 2008; Poff and others, 2009) because dams interrupt sediment fluxes and alter water-quality characteristics like transport of organic material, nutrients, dissolved oxygen, and temperature. In minimally altered rivers, channel morphology and associated physical habitats are expected to adjust to flow and sediment regimes imposed on them, with flow regime being the dominant control; however, in engineered rivers like the Lower Missouri River, the channel morphology is controlled mostly by river-training structures.

All 10 component models have a bounding box under primary ecological factors titled "Flow, geomorphology, hydraulics, and water-quality interactions." The complex linkages depicted among the specific factors (channel morphology, sediment regime, water-quality regime, and flow regime) illustrate the mutual adjustments and feedbacks that are known to exist in dynamic river channels. In more natural channels (for example, the Upper Missouri and Yellowstone Rivers) the adjustment might be lumped as the bounding box and could be considered to be dominated by flow regime; however, because channelization has been a major stressor to the Lower Missouri River and because channel reconfiguration has been a dominant management strategy (and RPA under the 2003 Biological Opinion), we separate the specific factors of the adjustment process. The adjustments are particularly important because they introduce uncertainty in predictions of the equilibrium end state of physical and water-quality habitat and when adjustment will be achieved. The complex configuration was retained for the upper river CEMs to address the potential effects of bank stabilization or possibly channel reconfiguration for habitat improvements. Because there is less direct engineering of the channel and banks in the upper river, the adjustments are likely less important in determining physical and chemical habitat.

Longitudinal connectivity is a primary ecological factor that operates at a broader scale and is therefore not shown as interacting within the bounding box. Longitudinal connectivity refers to the fragmentation of the main stem Missouri and Yellowstone Rivers by dams or reservoirs, a factor that has substantial importance in the pallid sturgeon life cycle because reproductive sturgeon have been documented migrating hundreds of kilometers upstream and larvae have the potential to drift and disperse hundreds to more than 1,000 kilometers downstream (Kynard and others, 2002; Braaten and others, 2008; DeLonay and others, 2009; Braaten and others, 2012; DeLonay and others, in press). Lack of longitudinal connectivity in the main stem and in some tributaries has limited upstream migration and downstream dispersal.

\section{Secondary Ecological Factors}

Secondary ecological factors are categorizations of conditions that result from primary ecological factors; categorizations are classified into bounding boxes of physical habitat, water quality (chemical habitat), and aquatic community composition (biotic habitat). Physical habitat, chemical habitat, and biotic habitat are each characterized in terms of dynamics (that is, described in terms of how habitat varies with time and through space according to concepts of analysis of hydrologic time series and patch dynamics; Pickett and White, 1985; Poff and others, 1997; The Nature Conservancy, 2005; Jacobson, 2013). Variability in space and time arises from the complex interactions of channel morphology, flow regimes, water-quality regimes, sediment regimes, and life cycles of aquatic organisms that may act as food sources, predators, competitors, or disease vectors.

The bounding boxes are common to all 10 component models but the specific factors and how they are linked vary by life stage and location. Within the physical habitat bounding box, hydraulics 
(spatial and temporal distributions of depth, velocity, and turbulence) and substrate characteristics are inter-related through the sediment transport capacity of the river, except in cases where substrate is associated with engineered structures (such as revetment rock) or bedrock exposures. Stability, quality, and quantity are particularly important aspects of substrate characteristics because of the benthic orientation of pallid sturgeon and, in particular, the role of substrate in spawning, fertilization, incubation, and hatching of adhesive eggs, and the production of forage for later life stages.

The water-quality bounding box contains specific factors that vary by life stage and location. Although many water-quality parameters related to habitat suitability could be defined, we emphasize water temperature, dissolved oxygen, turbidity, and contaminants as four factors of potential importance. The category of contaminants is particularly broad and may include dichlorodiphenyltrichloroethane (DDT) and its metabolites, polychlorinated biphenyls (PCBs), chlordane, mercury, selenium, and cadmium or other metals (Ruelle and Kennlyne, 1993), or other endocrine disrupting chemicals (DeLonay and others, 2009).

The aquatic community bounding box is also relatively broad in nature and varies considerably among component models. This bounding box includes elements of the aquatic community that contribute food to the pallid sturgeon or present sources of predation, competition, or disease (either as pathogens or as vectors for pathogens). For reproductive pallid sturgeon, the aquatic community includes the congeneric shovelnose sturgeon (Scaphirhynchus platorynchus), which has been thought to present a hybridization risk (Dryer and Sandvol, 1993; Schrey and others, 2011). Characteristics of the aquatic community are also linked in various ways to characteristics of physical and chemical habitat. The linkages within the "Secondary Ecological Factors" column provide potential for complex hypotheses to explain lack of recruitment in pallid sturgeon; for example, changes in physical habitat, although not affecting habitat use by pallid sturgeon directly, may have diminished habitat suitability for prey species, thereby diminishing food availability and consequent growth rates of juveniles and adults.

\section{Primary Biotic Response}

The "Primary Biotic Response" column is intended to describe specific biotic responses of pallid sturgeon to primary and secondary ecological factors. Primary biotic responses varied considerably among component models but were generally classified into three types: growth and condition, direct mortality, and reproductive behaviors. Growth and condition relate to factors that describe the bioenergetics of the fish (the integration of energy inputs and expenditures that determine somatic and gonadal growth). Lack of growth at a critical level may lead to starvation and mortality, or increase susceptibility to direct mortality. Direct mortality refers to sources of mortality not directly related to bioenergetics, including predation, removal (including harvest, entrainment, and impingement on screens, dredges, or props), toxins, and disease. Reproductive behaviors and synchrony are specific to spawning adults and include complex interactions between environmental variables and fish behavior that conceptually influence migration, aggregation, spawning site selection, and gamete placement during spawning and fertilization.

\section{Secondary Biotic Response}

All component models lead to one end point, the secondary biotic response or survival probability to the next life stage. Most, but not all, linkages from cause to effect propagate through each of the columns to the survival end point. Some linkages bypass parts of the structure. For example, removal of adult fish by harvest links directly to social, political, legal, and economic drivers of change (for example, through fish consumption advisories, poaching, and the worldwide market for caviar) instead of propagating through ecological factors. 
This structure - based on component models leading to survival probabilities for each life stage - is generally useful for a stage-based population-level model. One complication is dealing with transgenerational and trans-life stage effects. Such effects may not cause a decrease in survival for gametes or the next life stage but may instead manifest as lower survival probability during subsequent life stages. A trans-generational example is when lack of fitness in a reproductive adult results in delayed growth and lower fitness of embryos or larvae, resulting in increased mortality transitioning to later life stages. Trans-stage effects are situations where an individual survives a life stage but with reduced fitness so survival during later stages is diminished. Trans-generational or trans-life stage effects were not emphasized during the modeling workshops. If trans-generational or trans-life stage hypotheses emerge as priorities, they can be accommodated in the component models by defining another class of secondary biotic response that allows survival but results in enhanced mortality probability at later life stages. Trans-generational and trans-stage connections were added to the CEMs as a secondary ecological factor conditioning response and as secondary biotic responses transferring fitness or contaminant loads to the next life stage (fig. 7).

\section{Spatial Structure of the Conceptual Ecological Models}

Emerging data on population genetics support the notion that before development of the river, the metapopulation of pallid sturgeon was spatially structured, perhaps related to episodic genetic isolation during Pleistocene glacial advances and reorganization of the Missouri River drainage network (Campton and others, 2000; Tranah and others, 2004; Schrey and Heist, 2007; Schrey and others, 2011; DeLonay and others, in revision). One genetic group has been identified that is characteristic of the Upper Missouri River in Montana and North Dakota, another group is prominent in the Middle Mississippi and Atchafalaya Rivers, and a third genetically intermediate group is prominent in the Lower Missouri River, downstream from Gavins Point Dam (Schrey and Heist, 2007). The Upper Missouri River group was most distinct, and less genetic differentiation was observed between the Lower Missouri River and the Middle Mississippi and Atchafalaya Rivers groups.

Fragmentation of the Missouri River by dams exerts an additional, interacting spatial structure on the underlying, natural structure of the genetic subpopulations (fig. 6). There are no passage facilities at the main stem dams for volitional upstream passage. Only a few pallid sturgeon have been collected upstream from the Melvin Price Lock and Dam on the Mississippi River. Several shovelnose sturgeon have been documented passing over or around Intake Dam on the Yellowstone River (Tews, 1994; Braaten and Fuller, 2003) and four males and one female pallid sturgeon were documented bypassing the dam in 2014 by way of the natural side channel (Mike Backes, written commun., 2014). Currently, there is no evidence of recruitment upstream from Intake Dam. Downstream migration of juveniles or adults through reservoirs and dams is possible; 92 out of 3,721 stocked fish recaptured in the Lower Missouri River downstream from Gavins Point Dam were originally stocked upstream from Gavins Point Dam (Steffensen and Huenemann, 2014).

In addition to fragmentation exerted by the main stem reservoirs, the Lower Missouri and Middle Mississippi Rivers have substantial spatial variation associated with channel network structure (locations of tributaries), variable channelization and engineering, and locations of point sources of water-quality change (DeLonay and others, in revision). It has been hypothesized that variable physical and chemical habitat conditions along the Lower Missouri River may influence aggregation, spawning site selection, downstream dispersal of free-embryo larvae, and retention of early life stages.

The CEMs presented here recognize the significant physical and biological differences between the upper river and the lower river. Additional sources of spatial variation occur within these areas, and will be addressed in management hypotheses, but the present level of analysis is limited to 
comparing the upper and lower-rivers. The upper river (Upper Missouri and Yellowstone Rivers) is characterized by a distinct genetic group of fish whose reproductive range is constrained by Fort Peck Dam, Vandalia Dam on the Milk River, Intake Dam on the Yellowstone River (to some extent), and the headwaters of Lake Sakakawea. It has been hypothesized that dispersal distances have been reduced because of migration impediments at Fort Peck Dam, Vandalia Dam, or Intake Dam, resulting in insufficient distance for ontogenetic development of free embryos to the endogenously feeding larval stage and that conditions in reservoirs are not suitable for survival of free embryos (Kynard and others, 2007; Braaten and others, 2012; Guy and others, 2015). This hypothesis is supported by the lack of recruitment in the Yellowstone and Upper Missouri Rivers (U.S. Fish and Wildlife Service, 2000). In addition, the flow, temperature regime, and floodplain connectivity of the Upper Missouri River are strongly affected by releases from Fort Peck Dam. The releases from Fort Peck Dam result in decreases in water temperature in the spring and summer of about 2-3 degrees Celsius compared to the Yellowstone River, measured just upstream from the confluence (DeLonay and others, in revision).

The lower river, downstream from Gavins Point Dam, differs significantly in several respects, including having genetically different groups of pallid sturgeon, and differences in alteration of the flow regime, temperature regime, water quality, channel morphology, and longitudinal and lateral connectivity. The flow regime from Gavins Point Dam results from system operations to serve multiple purposes including navigation, hydropower, flood control, recreation, and endangered species purposes. Because Lewis and Clark Lake, formed by Gavins Point Dam, is relatively small and shallow compared to other Missouri River main stem reservoirs, water residence times are short and river flows downstream from the dam do not show the decreased temperatures observed downstream from Fort Peck Dam; instead, water temperature tracks closely with air temperature in the spring-fall time period (DeLonay and others, in revision). The extent of channel engineering is very different on the Lower Missouri River compared to the upper river. The first 59 miles downstream from Gavins Point Dam (at river mile 811 upstream from the Mississippi River) has complex channel morphology and diverse habitats despite being affected by extremely low sediment transport, channel incision, low turbidity, and approximately 33 percent bank stabilization. From river mile 753 to the confluence with the Mississippi River (river mile 0), the river is channelized for stability and maintenance of a navigation channel. Agricultural runoff and point discharges from industrial and municipal water treatment facilities potentially contribute to water-quality stressors in this section of river (U.S. Fish and Wildlife Service, 2014). Unlike the upper river, downstream dispersal distance for juvenile fish is essentially unlimited as fish may disperse into the Middle Mississippi River. What is unknown is whether the channelized system on the Lower Missouri River allows free embryos to be retained in suitable habitat before reaching starvation, or whether sites amenable to retention occur and will allow for growth and recruitment to older stages.

Although separate consideration of the upper and lower rivers is considered useful at this point in the analysis, we recognize that further spatial subdivisions of the upper and lower systems may be necessary as priority hypotheses are developed. Separate models may need to be developed for the Yellowstone and Upper Missouri Rivers, for example, or separate spatially explicit models may need to be developed to account for the punctuated gradient of environmental conditions downstream from Gavins Point Dam. A particularly important question is whether the Lower Missouri River should be considered as a single population of pallid sturgeon or should be divided into specific sub populations that use different parts of the river in their reproductive ranges.

Inter-reservoir reaches fit generally within these CEMs, but they have not been emphasized because cold, clear water and peaking flows in inter-reservoir reaches are generally inconsistent with the highly turbid, warm water conditions under which the fish evolved (U.S. Fish and Wildlife Service, 2014). Additional spatial detail, including the role of inter-reservoir reaches, will be addressed in a later phase of the prioritization process. 


\section{Descriptions of Component Models}

The following sections describe the specific component models with an emphasis on identifying the main hypotheses that are illustrated in the models. The models are presented graphically in the appendix and hypotheses thought to be important to survival probabilities (solid arrows) are labeled on the component CEMs and are cross-referenced in table 2. It should be noted that hypotheses are further refined and tested in subsequent steps of the EA process. Furthermore, some apparent inconsistencies between upper river and lower river hypotheses may be due to actual differences in conditions, and some may be due to the differences in expert opinions of the members of the two workshop groups.

\section{Upper River}

Upper river models share common characteristics on the left hand side of the CEM diagrams (appendix figures A1 through A5). In general, management actions involving reservoir engineering and operations are thought to have greater importance, whereas actions related to channel management and restoration are judged to have less importance, relative to the lower river.

\section{Pre-Spawn and Spawning Adults}

Pre-spawning adults are fish in the final stages of preparing for spawning. Spawning adults refers to female fish with oocytes that can be released and fertilized and male fish with flowing milt. The component model for this life stage is especially complex in depicting potential linkages from secondary ecological factors to primary biotic responses because of the many ways that reproductive behaviors may be linked to environmental variables. The end point for this CEM is viable embryos, which will result from successful spawn and fertilization.

Removal as a direct source of mortality is considered relatively certain and important and reflects concerns about losses to this small segment of the overall population that could result from poaching, impingement, entrainment, bycatch mortality in permitted fisheries, and removal of fish for broodstock use in hatcheries. Factors related to reproductive synchrony are shown as uncertain and important. In particular, characterization of the link from spawning site selection to survival to viable embryos arises from emerging telemetry information that documents non-systematic patterns of upstream and downstream migration behavior, suggesting a search for suitable spawning sites with suitable mates (Fuller and others, 2008; DeLonay and others, in revision). Migration is considered to be of moderate importance and moderate uncertainty, reflecting an analysis of telemetry data that shows that pallid sturgeon optimize migration pathways to minimize energy expenditures (Spindler and others, 2009; McElroy and others, 2012; DeLonay and others, in revision). Few hybrids have been collected in the upper river, so hybridization is thought to be relatively unimportant. Growth and condition factors in this life stage include gonad condition (fecundity). Growth and condition are linked with importance and substantial uncertainty of survival to viable embryos, reflecting the hypothesis that productivity and food availability may be important for fecundity.

A variety of secondary ecological factors link with highest importance and moderate uncertainty to reproductive behaviors. These represent competing (or inter-related) hypotheses for how environmental conditions affect reproductive behaviors and result in synchrony (that is, males and females in the same reproductive condition at the same time and in a location that is amenable to spawning and fertilization). 
Table 2. Candidate working set of biologically dominant hypotheses.

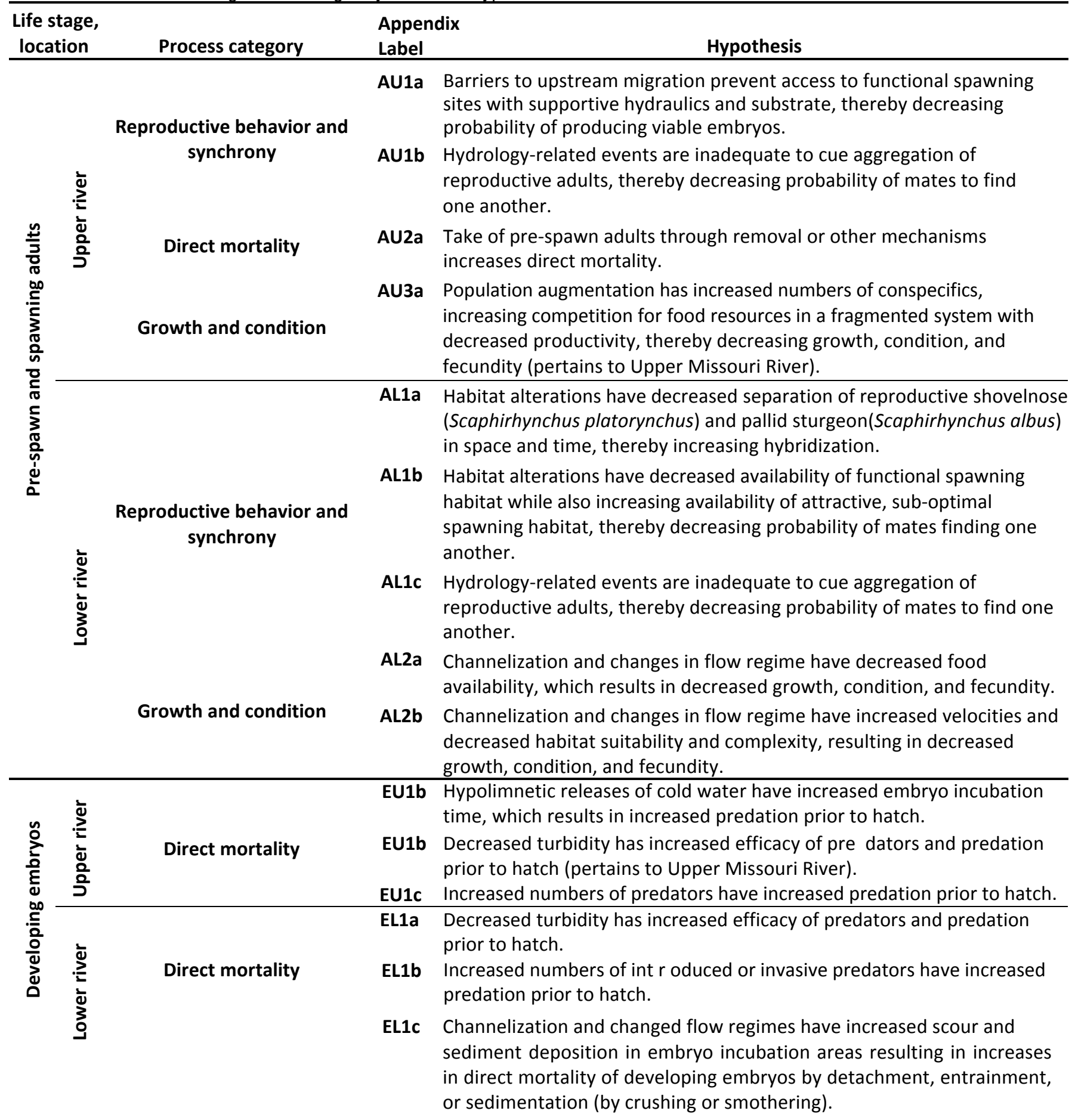


Table 2 . Candidate working set of biologically dominant hypotheses. -Continued

\begin{tabular}{|c|c|c|c|c|}
\hline \multicolumn{2}{|c|}{$\begin{array}{l}\text { Life stage, } \\
\text { location }\end{array}$} & Process category & \multirow{2}{*}{$\frac{\text { Label }}{\text { FU1a }}$} & Hypothesis \\
\hline \multirow{11}{*}{ 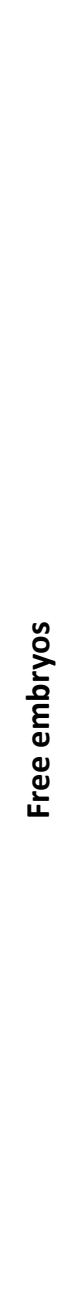 } & \multirow{6}{*}{ 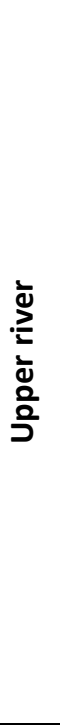 } & \multirow{5}{*}{ Direct mortality } & & $\begin{array}{l}\text { Hypolimnetic releases of cold water have increased embryo incubation time } \\
\text { which results in increased predation prior to settling. }\end{array}$ \\
\hline & & & FU1b & $\begin{array}{l}\text { Reservoirs have decreased turbidity, resulting in increased efficacy of } \\
\text { predators and increased direct mortality from predation prior to settling } \\
\text { (pertains to Upper Missouri River). }\end{array}$ \\
\hline & & & FU1c & $\begin{array}{l}\text { Increased numbers of predators has increased predation prior to settling } \\
\text { (pertains to Upper Missouri River). }\end{array}$ \\
\hline & & & FU1d & $\begin{array}{l}\text { Barriers to upstream migration limit available downstream dispersal distance } \\
\text { such that dispersing free embryos settle in unsuitable habitats in the } \\
\text { headwaters of downstream reservoirs, which increases direct mortality. }\end{array}$ \\
\hline & & & FU1e & $\begin{array}{l}\text { Barriers to upstream migration limit available downstream dispersal distance } \\
\text { such that dispersing free embryos settle in habitats that are not suitable for } \\
\text { first feeding, thereby increasing direct mortality. }\end{array}$ \\
\hline & & Growth and condition & FU2a & $\begin{array}{l}\text { Changes in flow regime, water quality, and (or) local habitat in settling areas } \\
\text { have decreased the prey base for first feeding, decreasing growth, condition, } \\
\text { and survival. }\end{array}$ \\
\hline & \multirow{5}{*}{ 离 } & \multirow{5}{*}{ Growth and condition } & FL1a & $\begin{array}{l}\text { Channelization has decreased post-hatch refugia in substrate interstices } \\
\text { resulting in increased direct mortality from predation. }\end{array}$ \\
\hline & & & FL1b & $\begin{array}{l}\text { Reservoirs have decreased turbidity, resulting in increased efficacy of predators } \\
\text { and increased direct mortality from predation prior to settling. }\end{array}$ \\
\hline & & & FL1c & $\begin{array}{l}\text { Channelization has decreased suitable hydraulics to intercept and retain } \\
\text { drifting free embryos, resulting in increased direct mortality by starvation } \\
\text { and inability to transition to first feeding. }\end{array}$ \\
\hline & & & FL2a & $\begin{array}{l}\text { Channelization has decreased supportive habitat conditions for first feeding } \\
\text { (increased velocities, lack of habitat complexity), decreasing growth, } \\
\text { condition, and survival. }\end{array}$ \\
\hline & & & FL2b & $\begin{array}{l}\text { Changes in flow regime, water quality, and/or channel complexity in settling } \\
\text { areas result in lack of suitable food for first feeding and decreases to growth, } \\
\text { condition, and survival. }\end{array}$ \\
\hline
\end{tabular}


Table 2. Candidate working set of biologically dominant hypotheses.-Continued

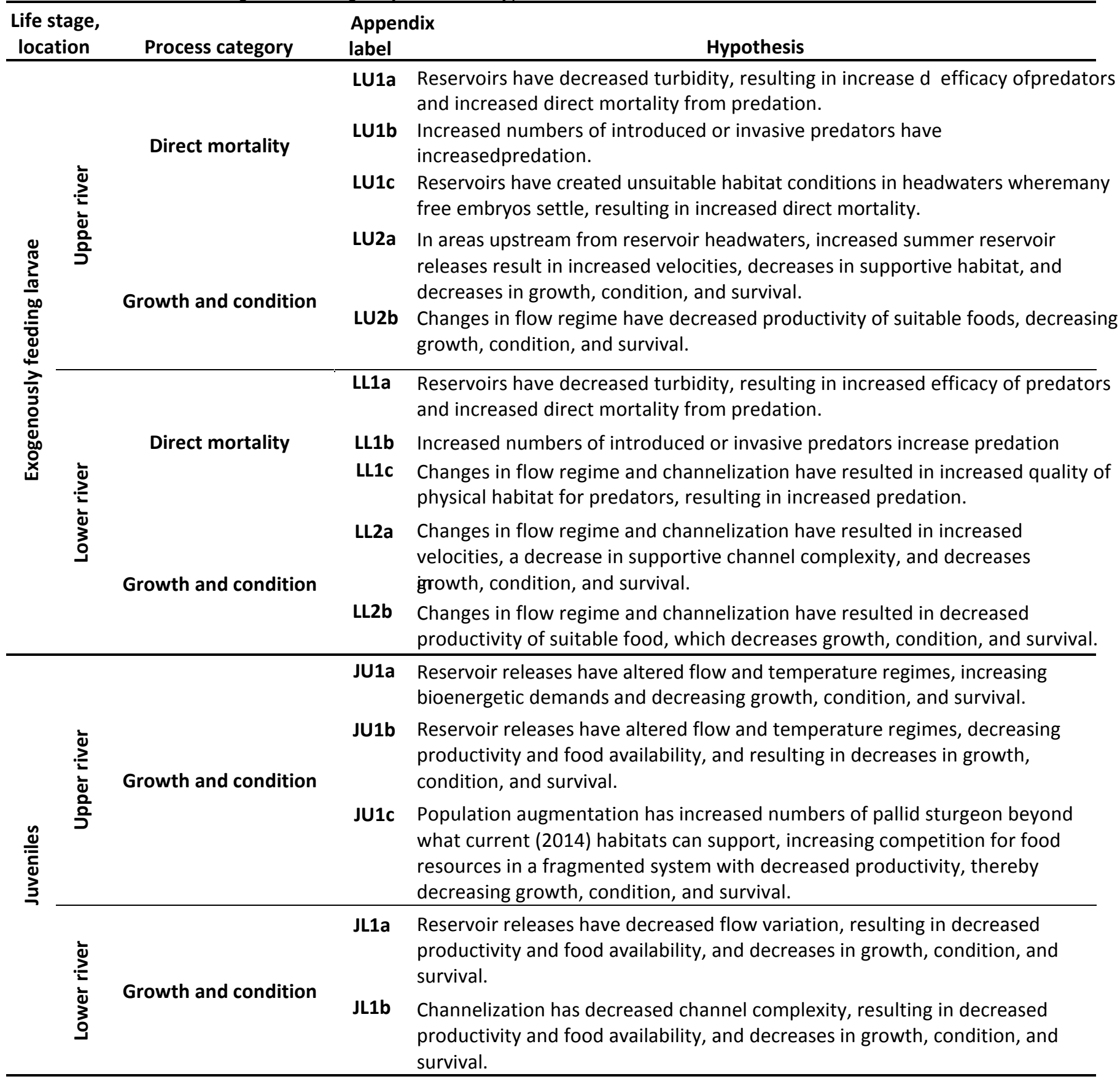

Physical habitat availability is dominantly a spatial issue controlled by local hydraulics and substrate, as well as longitudinal connectivity to allow habitats to be accessed. Water-quality factors also have a strong temporal component because they may act to cue or synchronize physiology and behaviors in time (DeLonay and others, 2009; DeLonay and others, in revision). Flow regime is shown as an important factor affecting physical habitat and water quality dynamics, as is water-quality regime (including temperature). The potential effect of flow regime on migration and aggregation behaviors is shown as filtered through physical habitat and water-quality dynamics, indicating the belief that the fish experience flow regime through some combination of hydraulics, temperature, or turbidity. 
Potential management actions that link to important primary ecological factors are reservoir operating rules, passage structures, water-quality structures, and dam locations. The strength of the linkages of management and restoration actions to primary ecological factors like flow and waterquality regimes is confounded somewhat by the fact that Upper Missouri and Yellowstone River segments are combined in these models. In the Yellowstone River, the flow regime is nearly natural and unmanaged, whereas in the Upper Missouri River, the flow and temperature regimes are highly affected by Fort Peck Dam; therefore, operating rules and water-quality structures do not apply on the Yellowstone River but may be considered on the Upper Missouri River. Passage structures apply mainly to the Yellowstone River for facilitation of migration over or around Intake Dam (and potentially another low-head dam at Forsyth, Montana); passage would only be considered relevant to the Upper Missouri River if migration up the Milk River or access to Fort Peck Lake was considered ecologically useful for pallid sturgeon. Downstream from the Upper Missouri/Yellowstone River, the headwaters of Lake Sakakawea are hypothesized to be unsupportive of early life stages because of unsuitable water-quality conditions and possible predation, relying on extrapolation of results from the headwaters of Fort Peck Dam(Guy and others, in press). Locations of dams are listed as a management action in relation to historical decisions to locate dams and to future decisions for dam locations or removals (however improbable).

\section{Developing Embryos}

Developing embryos refers to fertilized eggs prior to hatching. The temporal duration of the life stage is inversely related to temperature and lasts generally 5-8 days. The end stage of this CEM is the hatching of free embryos.

Survival to hatch is associated with processes the may impose direct mortality. Linkages from water-quality factors to growth and condition refer mainly to water temperature and dissolved oxygen around developing embryos. Direct mortality of embryos through contaminant toxicity is thought to have low importance and moderate uncertainty. Although there is historical documentation of organicchemical contaminant accumulation in eggs, laboratory studies indicate low mortality (Buckler, 2011; Missouri Department of Health and Senior Services, 2011). Exposure to industrial chemicals and pesticides also has been low in the upper river segments. Early detections of metals, PCBs, DDT, and organochlorine compounds in tissue samples from pallid sturgeon in the upper river (Ruelle and Kennlyne, 1993) have not been replicated in the last 20 years, indicating that contaminant exposure may have decreased with time. Metals associated with mining may be a significant source of contamination (Zelt and others, 1999). Linkages to reproductive behaviors at this life stage are included to indicate the role of hydraulics in determining whether fertilization occurs and whether embryos end up in the right type of substrate and velocity field where they can incubate.

Egg predation is shown as an important, moderately uncertain linkage from the aquatic community to survival. Processes of scour and sedimentation are shown as moderately important, highly uncertain links from physical habitat conditions to survival. Linkages from primary ecological factors to secondary factors are similar to the pre-spawning and spawning adult.

\section{Free Embryos}

The free embryo life stage is defined as a developing fish between hatch and first feeding. During this life stage the free embryo is no longer protected by the chorion and it relies on its yolk reserves to continue development. The life stage may last 7-12 or more days, depending on temperature (Kynard and others, 2002, 2007; Braaten and others, 2008, 2012). Field and laboratory studies continue to address key questions regarding behavior, downstream dispersal, and survival probabilities of sturgeon free embryos after hatch. Recent studies 
on other sturgeon species have questioned whether drift commences immediately upon hatch or whether instead sturgeon free embryos are more likely to survive if they remain in substrate interstices near the incubation site for some period of time, thereby allowing for more growth and improved swimming ability before initiating downstream dispersal and first feeding (McAdam, 2011; Crossman and Hildebrand, 2012; DeLonay and others, in revision).

Two hypotheses are thought to have high importance for survival of free embryos to the exogenously feeding larva stage. The first of these hypotheses addresses what happens if the free embryo is transported into lethal water-quality conditions, which has been suggested for free embryos that are transported into Lake Sakakawea (Braaten and others, 2012; Guy and others, in press). A related hypothesis links physical habitat to survival through growth and condition. This hypothesis addresses the situation when a free embryo is retained in a physically supporting habitat but one that lacks sufficient food quantity or quality, and the free embryo subsequently starves.

Two additional hypotheses rated as important depend in part on physical habitat and the aquatic community. Predators in the aquatic community are linked to direct mortality. Dispersing free embryos have poor predator avoidance capabilities and have an elevated risk of encountering a predator during the dispersal phase. Similarly, competition arises from elements of the aquatic community that would seek the same food sources as the free embryo when it transitions to first feeding.

Direct mortality by removal is also shown as a hypothesis to address the situation where free embryos are impinged on screens (for example, in municipal, industrial, or irrigation diversions) or otherwise entrained into water diversions. The importance of this process is currently thought to be relatively low, although the uncertainty is high.

Hypothesized linkages to management actions for this life stage are complex and, similar to previously discussed life stages, the hypotheses mix Upper Missouri and Yellowstone Rivers contexts. Reservoir operations on the Missouri River are strongly linked to flow regime, which may propagate through many secondary ecology factors. In particular, water velocities and consequent free-embryo transport rates can be affected by reservoir releases with high discharges resulting in generally high velocities and greater probability that free embryos would be transported into Lake Sakakawea. Reservoir operations or implementation of structures that could result in release of warmer water could increase developmental rate resulting in earlier transition to exogenously feeding larvae and shorter drift distances. Fish passage at Intake Diversion Dam on the Yellowstone River could increase available drift distance by allowing sturgeon to spawn farther upstream, if suitable spawning habitat exists. Optimization of spawning patches to increase retention of newly hatched free embryos or reconstruction of channel morphology to enhance interception of drifting free embryos could serve to decrease time and distance in the drifting stage, in either river. Finally, draw-down of Lake Sakakawea has the potential to create a longer drift distance and improve retention habitat by increasing the length of lotic habitat within the Upper Missouri River.

\section{Exogenously Feeding Larvae}

Exogenously feeding larvae are developing, feeding fish. This stage begins with first feeding and ends when fish transition to juvenile stage with a full complement of rays in all fins and the allometric relation between length and weight stabilizes. This stage usually completes before the first winter.

Predation is hypothesized to be an important component of natural mortality but with high uncertainty. Predation on this stage has been documented for other sturgeon species (Gadomski and Parsley, 2005). However, predation of larval pallid sturgeon has been shown in laboratory settings to be low when alternative prey is available, and insensitive to turbidity within a low to moderate range 
relative to post-impoundment turbidities (French and others, 2010; Blevins, 2011; French and others, 2013a). Predation is linked dominantly to the aquatic community but, of course, the aquatic community is linked in complex ways to various combinations of primary and secondary ecological factors.

Survival is also strongly linked to growth and condition through habitat suitability, food availability, and extent of competition. These growth and condition factors are similarly linked in complex ways to physical habitat, water quality, and aquatic community factors; the conceptual ecological model captures but does not disentangle these inter-relating hypotheses.

Removal through impingement or entrainment is also possible at this age, but no studies have addressed this in the Missouri River so uncertainty is high (Gutreuter and others, 2003).

Lethal water quality (anoxia) is retained as an important, but uncertain, hypothesis for this life stage based on the premise that dispersing free embryos may transition to exogenously feeding embryos after being transported into the headwaters of Lake Sakakawea.

Management actions that could influence survival are similar to the free embryo life stage, except there is more emphasis on actions that would increase food availability. Changes in flow and water-quality regimes (especially temperature) may increase or diminish physical habitat, water quality, and the aquatic community, with consequence for bioenergetics, growth, and condition that will allow larvae and juveniles to survive the winter. Because the larvae are feeding dominantly on zooplankton and invertebrates at this stage, conditions that increase these food types may be especially important. Overbank flows (floodplain or lateral connectivity) are hypothesized to be critical for stimulating food production on flood plains, for flushing food resources into the main stem habitats occupied by pallid sturgeon, and perhaps for increased retention of larvae (Bayley, 1991; Coutant, 2004; Thorp and others, 2006), although uncertainty is high because of the challenges of demonstrating the linkages among overbank flows, food resources, and occupancy of young fish. Implicit in the hypothesis is the idea that near-natural channel morphology in the upper river indicates that quantity and quality of in-channel habitat should not be limiting. Increased overbank flows can be accomplished by manipulating reservoir releases to increase flooding by removing engineered levees and by engineering channels to match the new hydrologic regime. These actions would involve socialeconomic tradeoffs such as loss of agricultural revenue. Because few levees exist along the Yellowstone and Upper Missouri Rivers, levee removal is not envisioned as a relevant action (under channel reconfiguration). Increased fish passage would result in greater overall area and food available to the fish population, whereas water-quality management would be linked to increased temperatures and productivity.

Juveniles

The juvenile life stage extends from when a fish has a full complement of fin rays to when it enters its first reproductive cycle, generally about 750 millimeters fork length (Albers and others, 2013; Steffensen and others, 2013b). During this period, a subadult stage may be defined when the fish's diet shifts from predominantly invertebrates to predominantly fish (Gerrity and others, 2006; Grohs and others, 2009; French and others, 2013b); however, the current conceptual ecological model groups these two life stages together pending further information indicating this transition is crucial to survival.

Emphasis during this life stage is on hypotheses relating survival to growth and condition, resulting dominantly from productivity of the aquatic community and water temperature (Kappenman and others, 2009). Physical habitat is thought to have a secondary effect, although similar to the larval life stage, productivity is thought to be linked to flow regime and channel morphology factors that stimulate food production and help flush food into pallid sturgeon habitats. Competition, predation, disease, and removal through entrainment and removal are also hypothesized to be important and varying from moderately to highly uncertain. 
Similar to the larval life stage, management actions envisioned to increase food resources would emphasize flow releases designed to connect to overbank areas or removal of impediments to overbank flooding to increase food production. There is uncertainty about the current production of forage in channel habitats. Increased fish passage would result in greater overall area and food available to the fish population whereas water-quality management would be linked to water temperatures and increased productivity.

\section{Lower River}

In comparison to the upper river, the lower river introduces an additional management opportunity in restoration of channel configurations (Jacobson and Galat, 2006). Also, the severity of flow-regime alteration diminishes in the downstream direction (Galat and Lipkin, 2000; Pegg and others, 2003), so reservoir management may assume less importance for some life stages in some parts of the lower river.

Definitions of life stages for the lower river models (figs. A6-A10) are identical to the upper rivers (figs. A1-A5) definitions.

\section{Pre-Spawn and Spawning Adults}

One hypothesis that was ranked important and relatively certain for this life stage relates survival to growth and condition resulting from a combination of physical habitat, water-quality dynamics, and aquatic community composition. Key linkages are hypothesized to be from physical habitat and temperature to habitat suitability, indicating a hypothesis about fundamental bioenergetics controls. A less certain linkage is from the aquatic community to food availability, indicating the potential for lack of prey fish to limit reproductive fitness of adult pallid sturgeon. Hybridization is also indicated as an important and relatively certain linkage from congenerics in the aquatic community (shovelnose sturgeon) to decreased probability of pallid sturgeon survival.

A variety of physical and water-quality factors are linked to reproductive behaviors and synchrony, indicating the strong and complex relations between physical and chemical habitat and reproductive behaviors at this life stage. Among these linkages is the hypothesis that reproductive aggregations and probabilities of suitable mates finding each other have been diminished by overprovision of hard, coarse substrate in bank revetment and channel-training structures (DeLonay and others, in revision). The premise for this hypothesis is that the small remaining reproductive population is too spread out to find suitable mates when females are ready to spawn, resulting in atresia or increased hybridization with shovelnose sturgeon. Spawning success could be increased by increasing numbers of reproductive adults, increasing quality of spawning patches to attract more of the existing population, or both. A related hypothesis that channelization has increased migratory energy expenditures, and thereby decreased reproductive fitness and the probability that mates can find each other, has not been supported by recent assessments of energy requirements of migratory pathways (McElroy and others, 2012). The result of multiple effects on survival of gametes is shown as relatively uncertain because of the competing and possibly inter-related hypotheses. Removal of pre-spawning and spawning adults has been assigned moderate importance and low uncertainty.

The lower river component models all show a greater role for channel morphology management compared to the upper river because of the extent of past alteration and the potential for reconfiguration of channel morphology as a restorative action. Channel morphology influences this life stage according to two dominant hypotheses. One hypothesis holds that adult reproductive fitness relates to growth and condition, indicated by food availability. Food availability, in turn, would be linked to habitat suitability for prey species, which could be increased through channel 
reconfigurations and flow management. Increased food would be linked to increased pallid sturgeon reproductive fitness, gamete quality, and embryo viability. The second hypothesis is that construction of more suitable and attractive spawning habitat in fewer locations would be sufficient to attract aggregations of reproductive pallid sturgeon.

Reservoir flow management actions link to flow regime and physical habitat, as well as directly to reproductive behaviors and synchrony. Managed flow regimes are shown interacting strongly with channel morphology to determine physical habitat dynamics, and also acting as environmental cues

that are hypothesized to help synchronize reproductive fish. Reproductive cues are hypothesized to be important but moderately uncertain, in part because they can arise through direct changes in discharge or uncertain combinations of discharge, temperature, turbidity, or other flow-related variables.

Management actions related to passage structures have been hypothesized to influence longitudinal connectivity with the potential to provide greater access to suitable spawning substrates. Rivers with impediments to passage include the Kansas and Osage Rivers, and there is potential that historical spawning areas on the main stem have been inundated upstream from Gavins Point Dam. Included in water quality structures are potential management actions to pass sediment through or around reservoirs. These actions would increase turbidity, result in decreased competition, and potentially increase reproductive fitness.

\section{Developing Embryos}

Dominant hypotheses for limited survival at the developing embryo stage hold that (1) spawning site hydraulics are not suitable for gamete placement and fertilization, and (or) that (2) spawning sites are susceptible to scour and deposition processes that either dislodge or bury incubating embryos, resulting in direct mortality. These hypotheses are supported by precise mapping of spawning locations on the Lower Missouri River that indicate spawning in zones of active sand transport in deep, fast, and turbulent water on outside bends (DeLonay and others, in revision), where fertilization may be problematic and scour and deposition threaten eggs during incubation. Predation is also given high importance and moderate uncertainty as a source of mortality based on studies of egg predation in other sturgeon species. Predation on pallid sturgeon embryos likely occurs but has not been documented. The effects of water quality on growth or lethal conditions for embryos, and the potential roles of disease on survival probabilities have relatively low importance but high uncertainty. The role of contaminants in decreasing embryo survival is given somewhat greater importance and has lower uncertainty because of the historically documented contaminant accumulation of industrial organic chemicals in eggs compared to recent laboratory studies indicating only slightly decreased embryo survival with increasing exposure to persistent organic chemicals (Buckler, 2011; Missouri Department of Health and Senior Services, 2011).

The dominant MRRP management action hypothesized for this life stage are channel reconfigurations that serve to decrease scour or sedimentation of eggs. Flow-regime management could also be useful in limiting scour and sedimentation in some cases but would be less specific than channel reconfiguration. Moreover, flow-regime management would have decreasing influence downstream because the effects of reservoir flow releases decrease in the downstream direction.

\section{Free Embryos}

The most important, but relatively uncertain, hypothesis relating to survival of free embryos is shown as the linkage from physical and chemical habitat to growth and condition. Increased growth and condition of free embryos are expected to result in increased survival when the free embryos can access suitable habitats characterized by hydraulics that are favorable for retention and water quality. The availability of sufficient, high-quality food is also linked as part of habitat suitability for growth and condition 
when the free embryo transitions to exogenous feeding. Additional hypotheses of moderate importance link physical and chemical habitat to survival probability through successful first feeding and lethal water quality (that is, high temperatures or low dissolved oxygen). The successful first feeding hypothesis relates to hydraulic conditions that allow drifting free embryos to "settle out" and be retained in supporting habitats, or hydraulic conditions that provide forage to areas where free embryos first require food. The lethal water quality hypothesis relates to the potential lethal effects of high water temperature and low dissolved oxygen that can develop at times in the Lower Missouri River during the summer (Blevins, 2011), and might be more prevalent in slow, deep water in wing-dike complexes. In addition, predation on free embryos is depicted as important but highly uncertain.

The primary ecological factor for this life stage is the interaction of channel morphology and flow regime that determines physical habitat dynamics and influences water-quality dynamics in drifting and retention habitats. The main management actions are (1) channel reconfigurations that would increase hydraulic diversity, encourage recirculating eddies to increase retention (interception habitats), and increase hydraulic flow resistance, thereby decreasing mean-channel velocities; and (2) flow management actions that would influence transport of free embryos by increasing or decreasing mean velocities. Both management actions depend, however, on an understanding that retention in particular locations would increase growth and condition relative to retention in other areas. This logic assumes that management actions to create retention areas account for the possibility of increased predation by native or non-native species and poor water quality. Management actions affecting water-quality regime are limited because sections of the river that would be directly affected by operational changes at Gavins Point Dam are limited in extent and many sources of water-quality stressors exist downstream that are beyond USACE management authorities. The possibility exists that channel reconfiguration could be designed to increase exchange between the main channel and marginal habitats, thereby minimizing stagnant water behind wing dikes where elevated temperatures and diminished dissolved oxygen may be likely.

\section{Exogenously Feeding Larvae}

The two important linkages identified for survival through the first winter are predation and growth and condition related to habitat suitability and food availability. The presence and efficacy of predators are linked to dynamics of predators' habitats (linkage from physical habitat to aquatic community) as well as habitats occupied by the larval pallid sturgeon. Habitat suitability is linked to hydraulics, temperature, and dissolved oxygen, which determine conditions conducive to growth. A moderately important, moderately uncertain linkage was identified between productivity of the aquatic community and food availability; assignment of moderate importance to this linkage is based on a lack of evidence for food availability constraints, although theory would support the idea that food availability and growth are critical for survival through the first winter (Post and Parkinson, 2001; Wildhaber and others, 2007; Wildhaber and others, 2011).

Management actions to increase survival at this stage that would propagate through relevant ecological factors are channel reconfigurations and reservoir operations and engineering. Channel reconfigurations have been implemented as the SWH creation RPA on the Lower Missouri River since the 2003 Biological Opinion. The SWH effort is reflected in this model as one approach to channel reconfiguration actions that alter channel morphology but also interact in complex ways with flow regime, sediment regime, and water quality to affect physical habitat dynamics, water-quality dynamics, and the aquatic community. The complexity of linkages and attendant uncertainties evident in this model underscore the understanding that although loss of shallow, slow-water habitat and habitat diversity has been well documented (Funk and Robinson, 1974; Hallberg and others, 1979; Hesse and Sheets, 1993; Jacobson and Galat, 2006), the specific mechanisms by which channel 
reconfiguration may support pallid sturgeon populations are poorly understood and have only recently begun to be a focus of descriptive field studies. Initial work to understand the distribution of Scaphirhynchus sturgeon during the latter part of the early life stage reflected in this CEM has demonstrated use of relatively fast velocity (that is, 0.5-0.7 meters per second bottom velocity) habitats, such as large channel sandbars and rootless dikes, that were generally adjacent to the river thalweg, and lack of use of habitats that had slow velocity or were largely disconnected from the thalweg (Ridenour and others, 2011). Moreover, channel configurations to support growth and condition of exogenously feeding larvae would be most effective when matched with locations to which free embryos and exogenously feeding larvae will disperse.

Flow management interacts with channel configuration to determine hydraulics, and to some extent, water quality in occupied habitats. Flow management also has the potential to create overbank flows that would connect with flood plains, boost primary and secondary productivity, and flush food resources into habitats occupied by pallid sturgeon (Bayley, 1991). The general hypothesis that periodic connection of channels with flood plains is necessary to spur system productivity is prominent in the large-river scientific literature (Junk and others, 1989; Sparks, 1995; Poff and others, 1997; Sparks and others, 1998; Tockner and others, 2000). In the CEM exercise, however, the hypothesis that increased food would increase survival at this stage was assigned only moderate importance. For the hypothesis to have greater support, data would need to demonstrate that: (1) food is a limiting factor in growth and condition of pallid sturgeon, (2) in-channel reconfiguration management actions are insufficient to reduce food limitation, (3) sufficient non-leveed riparian lands exist for flow pulses to be effective, and (4) floodplain lands can be connected with adequate magnitude, duration, and timing for discharges. The desire for private and public levee protection is much more prevalent on the Lower Missouri River compared to the upper river, but restoration of as much as 80,000 acres of floodplain conservation lands has been planned on the lower river (U.S. Army Corps of Engineers, 2003), which could provide for effective floodplain connectivity depending on hydrology and local channel condition (Jacobson and others, 2011). Sediment management to increase downstream turbidity is also hypothesized to decrease competition and predation (National Research Council, 2011). All management actions involving reservoir engineering and operations on the Lower Missouri River occur within the spatial context that magnitude of any action at Gavins Point Dam diminishes in relative importance as downstream tributaries affect fluxes of water, sediment, and water-quality constituents.

Juveniles

The dominant linkages to survival to adult are related to habitat suitability and food availability, in their importance to growth and condition (Spindler and others, 2012). Habitat suitability is strongly linked to hydraulic conditions that would support energy efficiency, and to hydraulics and aquatic community composition that would support food supply. Water temperature is also hypothesized to have a role in regulating growth and condition because it has been documented that optimal juvenile growth occurs at 28 degrees Celsius and temperatures greater than 35 degrees Celsius may be lethal (Chipps and others, 2008). Competition is recognized as an important and uncertain factor influencing growth and condition. Predation, disease, and removal (poaching, entrainment, or impingement) are recognized as moderately important contributors to mortality with varying uncertainty.

Potential management actions that would propagate to affect growth and condition of juveniles are similar to those discussed for larval fish. Channel reconfigurations are hypothesized to interact with flow regime, sediment regime, and water-quality characteristics to affect physical habitat, chemical habitat, and the aquatic community. A key difference may be the type of channel 
configuration and associated habitats that would be most effective in supporting different food sources. A design that encourages organic matter retention and mud substrate may, for example, support invertebrate production that would benefit young juveniles. Another design might provide hydraulics and substrate that would support prey-fish production, which would be more important for older juveniles that have transitioned to a piscivory (Gerrity and others, 2006; Wildhaber and others, 2011; French and others, 2013b). Hence, understanding this complex linkage may require increased understanding of the ecological factors that support prey populations (Ridenour and others, 2009). Channel configurations may also affect local water residence time and consequently temperature, and therefore may be designed to avoid lethal temperatures or optimize temperature for growth.

Flow management actions are similar to those for larval fish. Flow management would interact with channel configuration to determine hydraulics, and affect in-channel and overbank water quality and aquatic community dynamics. Flows that connect the floodplain to channel habitats would boost primary and secondary productivity, and flush food resources into main stem habitats. Additional food in the form of invertebrates may support pallid sturgeon directly or indirectly through prey-fish populations. Management actions involving reservoir engineering and operations will diminish in relative importance as downstream tributaries affect fluxes of water, sediment, and water-quality constituents.

\section{Summary and Conclusions}

This report documents the process of developing and refining conceptual ecological models for linking management actions to pallid sturgeon (Scaphirhynchus albus) population dynamics in the Missouri River. The general form of the conceptual ecological models (CEMs), represented by a population-level model and component life-stage models, was determined in workshops held in the summer of 2013. Subsequently, the Missouri River Pallid Sturgeon Effects Analysis team designed a general hierarchical structure for the component models, refined the graphical structure, and reconciled variation among the components and between models developed for the upper river (Upper Missouri and Yellowstone Rivers) and the lower river (Missouri River downstream from Gavins Point Dam). Importance scores attributed to the relations between primary biotic characteristics and survival were used to define a candidate set of working dominant hypotheses that are likely to be relevant to pallid sturgeon population dynamics.

The resulting CEMs are intended to be used as a foundation for adaptive management of pallid sturgeon populations in the Missouri River. The CEMs provide a structure for understanding and communicating complex abiotic and biotic processes in the Missouri River. In addition, the relations in the CEMs comprise a global set of hypotheses, which have the potential to explain some part of pallid sturgeon population dynamics. Although emphasis in the short term (2-5 years) will focus on relatively few specific hypotheses thought to be the most influential, the CEMs can be considered a reserve of hypotheses that can be revisited as needed if other hypotheses fail to explain observed population changes. 


\section{References Cited}

Albers, J.L., Wildhaber, M.L., and DeLonay, A.J., 2013, Gonadosomatic index and fecundity of Lower Missouri and Middle Mississippi River endangered pallid sturgeon estimated using minimally invasive techniques: Journal of Applied Ichthyology, v. 29, no. 5, p. 968-977, Available at $h t t p: / / d x . d o i . o r g / 10.1111 / j a i .12231$

Bajer, P.G., and Wildhaber, M.L., 2007, Population viability analysis of Lower Missouri River shovelnose sturgeon with initial application to the pallid sturgeon: Journal of Applied Ichthyology, v. 23, no. 4, p. 457-464, Available at http://dx.doi.org/10.1111/j.1439-0426.2007.00879.x

Bayley, P.B., 1991, The flood pulse advantage and the restoration of river-floodplain systems: Regulated Rivers: Research \& Management, v. 6, no. 2, p. 75-86, Available at $h t t p: / / d x . d o i . o r g / 10.1002 / r r r .3450060203$

Blevins, D.W., 2011, Water quality requirements, tolerances, and preferences of pallid sturgeon (Scaphirhychus albus) in the Lower Missouri River: U.S. Geological Survey Scientific Investigations Report 2011-5186, 20 p.

Braaten, P.J., and Fuller, D.B., 2002, Fort Peck flow modification biological data collection plan- end of an era: U.S. Geological Survey and Montana Fish, Wildlife \& Parks, 19 p., Available at http://mrnrc.com/image/cache/20110310-1B-0220pm.pdf

Braaten, P.J., Fuller, D.B., Holte, L.D., Lott, R.D., Viste, W., Brandt, T.F., and Legare, R.G., 2008, Drift dynamics of larval pallid sturgeon and shovelnose sturgeon in a natural side channel of the Upper Missouri River, Montana: North American Journal of Fisheries Management, v. 28, no. 3, p. 808-826, Available at $h t t p: / / d x . d o i . o r g / 10.1577 / m 06-$ 285.1

Braaten, P.J., Fuller, D.B., Lott, R.D., Haddix, T.M., Holte, L.D., Wilson, R.H., Bartron, M.L., Kalie, J.A., DeHaan, P.W., Ardren, W.R., Holm, R.J., and Jaeger, M.E., 2012, Natural growth and diet of known-age pallid sturgeon (Scaphirhynchus albus) early life stages in the upper Missouri River basin, Montana and North Dakota: Journal of Applied Ichthyology, v. 28, no. 4, p. 496-504, Available at $h$ ttp://dx.doi.org/10.1111/j.1439-0426.2012.01964.x

Buckler, J., 2011, Persistent organic pollutant effect on middle Mississippi River Scaphirhynchus sturgeon reproduction and early life stages: Columbia, Mo., University of Missouri, 154 p., Available at https://mospace.umsystem.edu/xmlui/bitstream/handle/10355/14530/research.pdf?sequence $=2$

Campton, D.E., Bass, A.L., Chapman, F.A., and Bowen, B.W., 2000, Genetic distiniction of pallid, shovelnose, and Alabama sturgeon- emerging species and the U.S. Endangered Species Act: Conservation Genetics, v. 1, p. 17-32, Available at $h$ ttp://link.springer.com/article/10.1023\%2FA\%3A1010121417487

Chipps, S.R., Klumb, R.A., and Wright, E.B., 2008, Development and application of juvenile pallid sturgeon bioenergetics model: South Dakota Game, Fish and Parks, 40 p.

Coutant, C.C., 2004, A riparian habitat hypothesis for successful reproduction of white sturgeon: Reviews in Fisheries Science, v. 12, no. 1, p. 23-73, Available at $h t t p: / / d x . d o i . o r g / 10.1080 / 10641260490273023$

Crossman, J.A., and Hildebrand, L.R., 2014, Evaluation of spawning substrate enhancement for white sturgeon in a regulated river- effects on larval retention and dispersal: River Research and Applications, v. 30, no. 1, p. 1-10, Available at $h$ ttp://dx.doi.org/10.1002/rra.2620

Delonay, A.J., Jacobson, R.B., Chojnacki, K.A., Braaten, P.J., Bulliner, E.A., Elliott, C.M., Erwin, S.O., Fuller, D.B., Haas, J.D., Ladd, H.L.A., Mestl, G.E., Papoulias, D.M., and Wildhaber, M.L., in press, Ecological requirements for pallid sturgeon reproduction and recruitment in the Missouri River- a synthesis of science, 2005-2012: U.S. Geological Survey Scientific Investigations Report 2015-XXXX, 162 p.

DeLonay, A.J., Jacobson, R.B., Papoulias, D.M., Simpkins, D.G., Wildhaber, M.L., Reuter, J.M., Bonnot, T.W., Chojnacki, K.A., Korschgen, C.E., Mestl, G., and Mac, M.J., 2009, Ecological requirements for pallid sturgeon reproduction and recruitment in the Lower Missouri River- A research synthesis 2005-08: U.S. Geological Survey Scientific Investigations Report 2009-5201, 59 p.

Doyle, M., Murphy, D., Bartell, S., Farmer, A., Guy, C.S., Palmer, M., and Turner, R., 2011, Final report on spring pulses and adaptive management- Missouri River Recovery Program Independent Science Advisory Panel: U.S. Institute for Environmental Conflict Resolution, 58 p., Available at http://projects.ecr.gov/moriversciencepanel/pdfs/MRISAPFinalReportSpringPulse-AdaptMgt113011.pdf

Dryer, M.P., and Sandvol, A.J., 1993, Recovery Plan for the Pallid Sturgeon (Scaphirhynchus albus): U.S. Fish and Wildlife Service, $63 \mathrm{p}$.

Federal Register, 1990, Determination of endangered status for the pallid sturgeon: Washington, D.C., Government Printing Office, v. 55 FR, p. 36641-36647

French, W.E., Graeb, B.D.S., Bertrand, K.N., Chipps, S.R., and Klumb, R.A., 2013a, Size-dependent trophic patterns of pallid sturgeon and shovelnose sturgeon in a large river system: Journal of Fish and Wildlife Management, v. 4, no. 1, p. 41-52, Available at http://dx.doi.org/10.3996/022012-jfwm-013 
French, W.E., Graeb, B.D.S., Chipps, S.R., Bertrand, K.N., Selch, T.M., and Klumb, R.A., 2010, Vulnerability of age-0 pallid sturgeon Scaphirhynchus albus to fish predation: Journal of Applied Ichthyology, v. 26, no. 1, p. 6-10, Available at $h t t p: / / d x . d o i . o r g / 10.1111 / j .1439-0426.2009 .01356 . x$

French, W.E., Graeb, B.D.S., Chipps, S.R., and Klumb, R.A., 2013b, Vulnerability of age-0 pallid sturgeon Scaphirhynchus albus to predation; effects of predator type, turbidity, body size, and prey density: Environmental Biology of Fishes, v. 97, no. 6, p. 635-646, Available at http://dx.doi.org/10.1007/s10641-013-0166-y

Fuller, D.B., Jaeger, M.E., and Webb, M., 2008, Spawning and associated movement patterns of pallid sturgeon in the lower Yellowstone River. Report submitted to the Western Area Power Administration, Upper basin pallid sturgeon work group.: Montana Fish, Wildlife and Parks, Available at http://moriverrecovery.usace.army.mil/mrrp/MRRP_PUB_DEV.download_documentation?p_file=7094

Funk, J.L., and Robinson, J.W., 1974, Changes in the channel of the lower Missouri River and effects on fish and wildlife: Missouri Department of Conservation, p. 1-53

Gadomski, D.M., and Parsley, M.J., 2005, Vulnerability of young white sturgeon, Acipenser transmontanus, to predation in the presence of alternative prey: Environmental Biology of Fishes, v. 74, no. 3-4, p. 389-396, Available at http://dx.doi.org/10.1007/s10641-005-3038-2

Galat, D.L., and Lipkin, R., 2000, Restoring ecological integrity of great rivers- historical hydrographs aid in defining reference conditions for the Missouri River: Hydrobiologia, v. 422, p. 29-48, Available at http://dx.doi.org/10.1023/A:1017052319056

Gentile, J.H., Harwell, M.A., Cropper, W., Harwell, C.C., DeAngelis, D., Davis, S., Ogden, J.C., and Lirman, D., 2001, Ecological conceptual models- a framework and case study on ecosystem management for South Florida sustainability: Science of the Total Environment, v. 274, no. 1-3, p. 231-253, Available at http://dx.doi.org/10.1016/S0048-9697(01)00746-X

Gerrity, P., Guy, C.S., and Gardner, W.M., 2006, Juvenile pallid sturgeon are piscivorous- A call for conserving native cyprinids: Transactions of the American Fisheries Society, v. 135, no. 3, p. 604-609, Available at http://dx.doi.org/10.1577/t05-122.1

Grohs, K.L., Klumb, R.A., Chipps, S.R., and Wanner, G.A., 2009, Ontogenetic patterns in prey use by pallid sturgeon in the Missouri River, South Dakota and Nebraska: Journal of Applied Ichthyology, v. 25, p. 48-53, Available at http://dx.doi.org/10.1111/j.1439-0426.2009.01279.x

Gutreuter, S., Dettmers, J.M., and Wahl, D.H., 2003, Estimating mortality rates of adult fish from entrainment through the propellers of river towboats: Transactions of the American Fisheries Society, v. 132, no. 4, p. 646-661, Available at http://dx.doi.org/10.1577/T01-098

Guy, C.S., Treanor, H.B., Kappenman, K.M., Scholl, E.A., Ilgen, J.E., and Webb, M.A.H., 2015, Broadening the regulatedriver management paradigm- a case study of the forgotten dead zone hindering pallid sturgeon recovery: Fisheries, v. 0, no. 1, p. 6-14, Available at http://dx.doi.org/10.1080/03632415.2014.987236

Hallberg, G.R., Harbaugh, J.M., and Witinok, P.M., 1979, Changes in the channel area of the Missouri River in Iowa, 1879-1976: Iowa Geological Survey, 32 p.

Harwell, M.A., Myers, V., Young, T., Bartuska, A., Gassman, N., Gentile, J.H., Harwell, C.C., Appelbaum, S., Barko, J., Causey, B., Johnson, C., McLean, A., Smola, R., Templet, P., and Tosini, S., 1999, A framework for an ecosystem integrity report card: Bioscience, v. 49, no. 7, p. 543-556, Available at http://dx.doi.org/10.2307/1313475

Hesse, L.W., and Sheets, W., 1993, The Missouri River hydrosystem: Fisheries, v. 18, no. 5, p. 5-14, Available at http://dx.doi.org/10.1577/1548-8446(1993)018<0005:tmrh>2.0.co;2

Jacobson, R.B., 2013, Riverine habitat dynamics, chap. of Shroder, J.F., Butler, D.R., and Hupp, C.R. eds., Treatise on Geomorphology, v. 12: San Diego, Academic Press, p. 6-19

Jacobson, R.B., and Berkley, J., 2011, Conceptualizing and communicating ecological river restoration, chap. of Simon, A., Bennet, S., and Castro, J. eds., Stream Restoration in Dynamic Fluvial Systems- Scientific Approaches, Analyses and Tools: AGU Geophysical Monograph, v. 194, p. 22

Jacobson, R.B., and Galat, D.L., 2006, Flow and form in rehabilitation of large-river ecosystems: An example from the Lower Missouri River: Geomorphology, v. 77, no. 3-4, p. 249-269, Available at http://dx.doi.org/10.1016/j.geomorph.2006.01.014

Jacobson, R.B., and Galat, D.L., 2008, Design of a naturalized flow regime-an example from the Lower Missouri River, U.S.A.: Ecohydrology, v. 1, no. 2, p. 81-104, Available at http://dx.doi.org/10.1002/eco.9

Jacobson, R.B., Janke, T.P., and Skold, J.J., 2011, Hydrologic and geomorphic considerations in restoration of riverfloodplain connectivity in a highly altered river system, Lower Missouri River, U.S.A.: Wetlands Ecology and Management, v. 19, no. 4, p. 295-316, Available at http://dx.doi.org/10.1007/s11273-011-9217-3

Junk, W.J., Bayley, P.B., and Sparks, R.E., 1989, The flood pulse concept in river-floodplain systems: Canadian Special Publication of Fisheries and Aquatic Sciences, v. 106, p. 110-127 
Kappenman, K.M., Fraser, W.C., Toner, M., Dean, J., and Webb, M.A.H., 2009, Effect of temperature on growth, condition, and survival of juvenile shovelnose sturgeon: Transactions of the American Fisheries Society, v. 138, no. 4, p. 927-937, Available at <Go to ISI>://WOS:000268501300019

Kynard, B., Henyey, E., and Horgan, M., 2002, Ontogenetic behavior, migration, and social behavior of pallid sturgeon, Scaphirhynchus albus, and shovelnose sturgeon, S. platorynchus, with notes on the adaptive significance of body color: Environmental Biology of Fishes, v. 63, no. 4, p. 389-403, Available at http://dx.doi.org/10.1023/A:1014950202783

Kynard, B., Parker, E., Pugh, D., and Parker, T., 2007, Use of laboratory studies to develop a dispersal model for Missouri River pallid sturgeon early life intervals: Journal of Applied Ichthyology, v. 23, no. 4, p. 365-374, Available at http://dx.doi.org/10.1111/j.1439-0426.2007.00908.x

Lubinski, K.S., and Barko, J.W., 2003, Upper Mississippi River-Illinois Waterway System Navigation Feasibility StudyEnvironmental Science Panel Report: U.S. Army Corps of Engineers ENV Report 52, 79 p.

McAdam, S.O., and Jonsson, B., 2011, Effects of substrate condition on habitat use and survival by white sturgeon (Acipenser transmontanus) larvae and potential implications for recruitment: Canadian Journal of Fisheries and Aquatic Sciences, v. 68, no. 5, p. 812-822, Available at http://dx.doi.org/10.1139/f2011-021

McElroy, B., DeLonay, A., and Jacobson, R., 2012, Optimum swimming pathways of fish spawning migration in rivers: Ecology, v. 93, no. 1, p. 29-34, Available at http://dx.doi.org/10.1890/11-1082.1

Missouri Department of Health and Senior Services, 2011, 2011 Fish advisory: Missouri Department of Health and Senior Services, 22 p.

Murphy, D.D., and Weiland, P.S., 2011, The route to best science in implementation of the Endangered Species Act's consultation mandate- the benefits of structured effects analysis: Environ Manage, v. 47, no. 2, p. 161-172, Available at http://www.ncbi.nlm.nih.gov/pubmed/21161526

National Research Council, 2011, Missouri River planning- recognizing and incorporating sediment management: Washington, D.C., The National Academies Press, 165 p.

National Research Council Committee on Missouri River Ecosystem Science, 2002, The Missouri River ecosystemsexploring the prospects for recovery: Washington, D.C., The National Academies Press, 188 p.

Pegg, M.A., Pierce, C.L., and Roy, A., 2003, Hydrological alteration along the Missouri River basin- a time series approach: Aquatic Science, v. 65, no. 1, p. 63-72, Available at http://dx.doi.org/10.1007/s000270300005

Pickett, S.T.A., and White, P.S., 1986, The ecology of natural disturbance and patch dynamics: Orlando, Fla., Academic Press, 472 p.

Poff, N.L., Allan, J.D., Bain, M.B., Karr, J.R., Prestegaard, K.L., Richter, B.D., Sparks, R.E., and Stromberg, J.C., 1997, The natural flow regime: BioScience, v. 47, no. 11, p. 769-784, Available at http://dx.doi.org/10.2307/1313099

Poff, N.L., Richter, B.D., Arthington, A.H., Bunn, S.E., Naiman, R.J., Kendy, E., Acreman, M., Apse, C., Bledsoe, B.P., Freeman, M.C., Henriksen, J., Jacobson, R.B., Kennen, J.G., Merritt, D.M., O'Keeffe, J.H., Olden, J.D., Rogers, K., Tharme, R.E., and Warner, A., 2010, The ecological limits of hydrologic alteration (ELOHA)- a new framework for developing regional environmental flow standards: Freshwater Biology, v. 55, no. 1, p. 147-170, Available at $h t t p: / / d x . d o i . o r g / 10.1111 / j .1365-2427.2009 .02204 . x$

Post, J.R., and Parkinson, E.A., 2001, Energy allocation strategy in young fish- Allometry and survival: Ecology, v. 82, no. 4, p. 1040-1051, Available at http://dx.doi.org/10.1890/0012-9658(2001)082[1040:Easiyf]2.0.Co;2

Ridenour, C.J., Doyle, W.J., and Hill, T.D., 2011, Habitats of age-0 sturgeon in the Lower Missouri River: Transactions of the American Fisheries Society, v. 140, no. 5, p. 1351-1358, Available at http://dx.doi.org/10.1080/00028487.2011.620493

Ridenour, C.J., Starostka, A.B., Doyle, W.J., and Hill, T.D., 2009, Habitat used by Macrhybopsis chubs associated with channel modifying structures in a large regulated river- implications for river modification: River Research and Applications, v. 25, no. 4, p. 472-485, Available at http://dx.doi.org/10.1002/Rra.1175

Rieman, B., Peterson, J.T., Clayton, J., Howell, P., Thurow, R., Thompson, W., and Lee, D., 2001, Evaluation of potential effects of federal land management alternatives on trends of salmonids and their habitats in the interior Columbia River basin: Forest Ecology and Management, v. 153, no. 1-3, p. 43-62, Available at http://dx.doi.org/10.1016/S0378-1127(01)00453-4

Ruelle, R., and Keenlyne, K.D., 1993, Contaminants in Missouri River pallid sturgeon: Bull.Environ. Contam. Toxicol., v. 50, no. 6, p. 898-906, Available at http://www.ncbi.nlm.nih.gov/pubmed/8495068

Schrey, A.W., Boley, R., and Heist, E.J., 2011, Hybridization between pallid sturgeon Scaphirhynchus albus and shovelnose sturgeon Scaphirhynchus platorynchus: J Fish Biol, v. 79, no. 7, p. 1828-1850, Available at http://www.ncbi.nlm.nih.gov/pubmed/22141890

Schrey, A.W., and Heist, E.J., 2007, Stock structure of pallid sturgeon analyzed with microsatellite loci: Journal of Applied Ichthyology, v. 23, no. 4, p. 297-303, Available at http://dx.doi.org/10.1111/j.1439-0426.2007.00881.x 
Sparks, R.E., 1995, Need for ecosystem management of large rivers and their floodplains: BioScience, v. 45, no. 3, p. 168182, Available at $<$ Go to ISI $>$ ://WOS:A1995QH75600010

Sparks, R.E., Nelson, J.C., and Yin, Y., 1998, Naturalization of the flood regime in regulated rivers: Flooding: Natural and Managed, v. 48, no. 9, p. 706-720, Available at http://dx.doi.org/10.2307/1313334

Spindler, B.D., Chipps, S.R., Klumb, R.A., Graeb, B.D.S., and Wimberly, M.C., 2012, Habitat and prey availability attributes associated with juvenile and early adult pallid sturgeon occurrence in the Missouri River, U.S.A.: Endangered Species Research, v. 16, no. 3, p. 225-234, Available at $h t t p: / / d x . d o i . o r g / 10.3354 /$ esr00408

Spindler, B.D., Chipps, S.R., Klumb, R.A., and Wimberly, M.C., 2009, Spatial analysis of pallid sturgeon Scaphirhynchus albus distribution in the Missouri River, South Dakota: Journal of Applied Ichthyology, v. 25, p. 8-13, Available at http://dx.doi.org/10.1111/j.1439-0426.2009.01283.x

Steffensen, K.D., and Huenemann, T., 2014, Pallid sturgeon stocking and recapture synthesis report for the Lower Missouri River: Nebraska Game and Parks Commission, 15 p.

Steffensen, K.D., Pegg, M.A., and Mestl, G., 2013a, Population prediction and viability model for pallid sturgeon (Scaphirhynchus albus, Forbes and Richardson, ) in the Lower Missouri River: Journal of Applied Ichthyology, v. 29, no. 5, p. 984-989, Available at http://dx.doi.org/10.1111/jai.12277

Steffensen, K.D., Pegg, M.A., and Mestl, G.E., 2013b, Population characteristics of pallid sturgeon (Scaphirhynchus albus(Forbes \& Richardson, )) in the Lower Missouri River: Journal of Applied Ichthyology, v. 29, no. 4, p. 687695, Available at http://dx.doi.org/10.1111/jai.12196

Stewart-Koster, B., Bunn, S.E., MacKay, S.J., Poff, N.L., Naiman, R.J., and Lake, P.S., 2010, The use of Bayesian networks to guide investments in flow and catchment restoration for impaired river ecosystems: Freshwater Biology, v. 55, no. 1, p. 243-260, Available at $h t t p: / / d x . d o i . o r g / 10.1111 / j .1365-2427.2009 .02219 . x$

Tews, A., 1994, Pallid sturgeon and shovelnose sturgeon in the Missouri River from Fort Peck Dam to Lake Sakakawea and in the Yellowstone from Intake to its mouth -- Fort Peck Pallid Sturgeon Study: Montana Fish, Wildlife and Parks, 50 p.

The Nature Conservancy, 2005, Indicators of hydrologic alteration, Version 7, user's manual, 42 p.

Thorp, J.H., Thoms, M.C., and Delong, M.D., 2006, The riverine ecosystem synthesis- Biocomplexity in river networks across space and time: River Research and Applications, v. 22, no. 2, p. 123-147, Available at http://dx.doi.org/10.1002/Rra.901

Tockner, K., Malard, F., and Ward, J.V., 2000, An extension of the flood pulse concept: Hydrological Processes, v. 14, no. 16-17, p. 2861-2883, Available at http://dx.doi.org/10.1002/1099-1085(200011/12)14:16/17<2861::AidHyp124>3.0.Co;2-F

Tranah, G., Campton, D.E., and May, B., 2004, Genetic evidence for hybridization of pallid and shovelnose sturgeon: J Hered, v. 95, no. 6, p. 474-480, Available at http://www.ncbi.nlm.nih.gov/pubmed/15475392

U.S. Army Corps of Engineers, 1981, Missouri River bank stabilization and navigation project final feasibility report and final EIS for the fish and wildlife mitigation plan: U.S. Army Corps of Engineers, Northwest Division

U.S. Army Corps of Engineers, 2001, Summary Missouri River Revised Draft Environmental Impact Statement - Master Water Control Manual Review and Update: U.S. Army Corps of Engineers, 28 p.

U.S. Army Corps of Engineers, 2003, Final supplemental environmental impact statement (FSEIS) for the modified Missouri River Fish and Wildlife Mitigation Project: U.S. Army Corps of Engineers

U.S. Fish and Wildlife Service, 2000, Biological opinion on the operation of the Missouri River main stem reservoir system, operation and maintenance of the Missouri River bank stabilization and navigation project, and operation of the Kansas River reservoir system: U.S. Fish and Wildlife Service, 296 p.

U.S. Fish and Wildlife Service, 2003, Amendment to the 2000 biological opinion on the operation of the Missouri River main stem reservoir system, operation and maintenance of the Missouri River bank stabilization and navigation project, and operation of the Kansas River reservoir system: U.S. Army Corps of Engineers, 12 p.

U.S. Fish and Wildlife Service, 2014, Revised recovery plan for the pallid sturgeon (Scaphirhynchus albus): U.S. Fish and Wildlife Service, $115 \mathrm{p}$.

Walters, C., 1986, Adaptive management of renewable resources: New York, Macmillan, 374 p.

Walters, C., Korman, J., Stevens, L.E., and Gold, B., 2000, Ecosystem modeling for evaluation of adaptive management policies in the Grand Canyon: Conservation Ecology, v. 4, no. 2, p. art. no.-1 1-34, Available at http://dlc.dlib.indiana.edu/dlc/bitstream/handle/10535/2703/32.pdf?sequence=1\&isAllowed $=y$

Wildhaber, M.L., DeLonay, A., Papoulias, D.M., Galat, D.L., Jacobson, R.B., Simpkins, D.G., Braaten, P.J., Korschgen, C.E., and Mac, M.J., 2007, A conceptual life-history model for pallid and shovelnose sturgeon: U.S. Geological Survey Circular 1315, $18 \mathrm{p}$.

Wildhaber, M.L., DeLonay, A.J., Papoulias, D.M., Galat, D.L., Jacobson, R.B., Simpkins, D.G., Braaten, P.J., Korschgen, C.E., and Mac, M.J., 2011, Identifying structural elements needed for development of a predictive life-history 
model for pallid and shovelnose sturgeons: Journal of Applied Ichthyology, v. 27, no. 2, p. 462-469, Available at http://dx.doi.org/10.1111/j.1439-0426.2011.01731.x

Woodward, A., Schreiner, E.G., Crain, P., Brenkman, S.J., Happe, P.J., Acker, S.A., and Hawkins-Hoffman, C., 2008, Conceptual models for research and monitoring of Elwha dam removal - Management perspective: Northwest Science, v. 82, p. 59-71, Available at http://dx.doi.org/10.3955/0029-344X-82.S.I.59

Zelt, R.B., Boughton, G., Miller, K.A., Mason, J.P., and Gianakos, L.M., 1999, Environmental setting of the Yellowstone River basin, Montana, North Dakota, and Wyoming: U.S. Geological Survey Water-Resources Investigations Report 98-4269, 113 p. 


\section{Appendix}

Graphical presentations of conceptual ecological models by life stage and location.

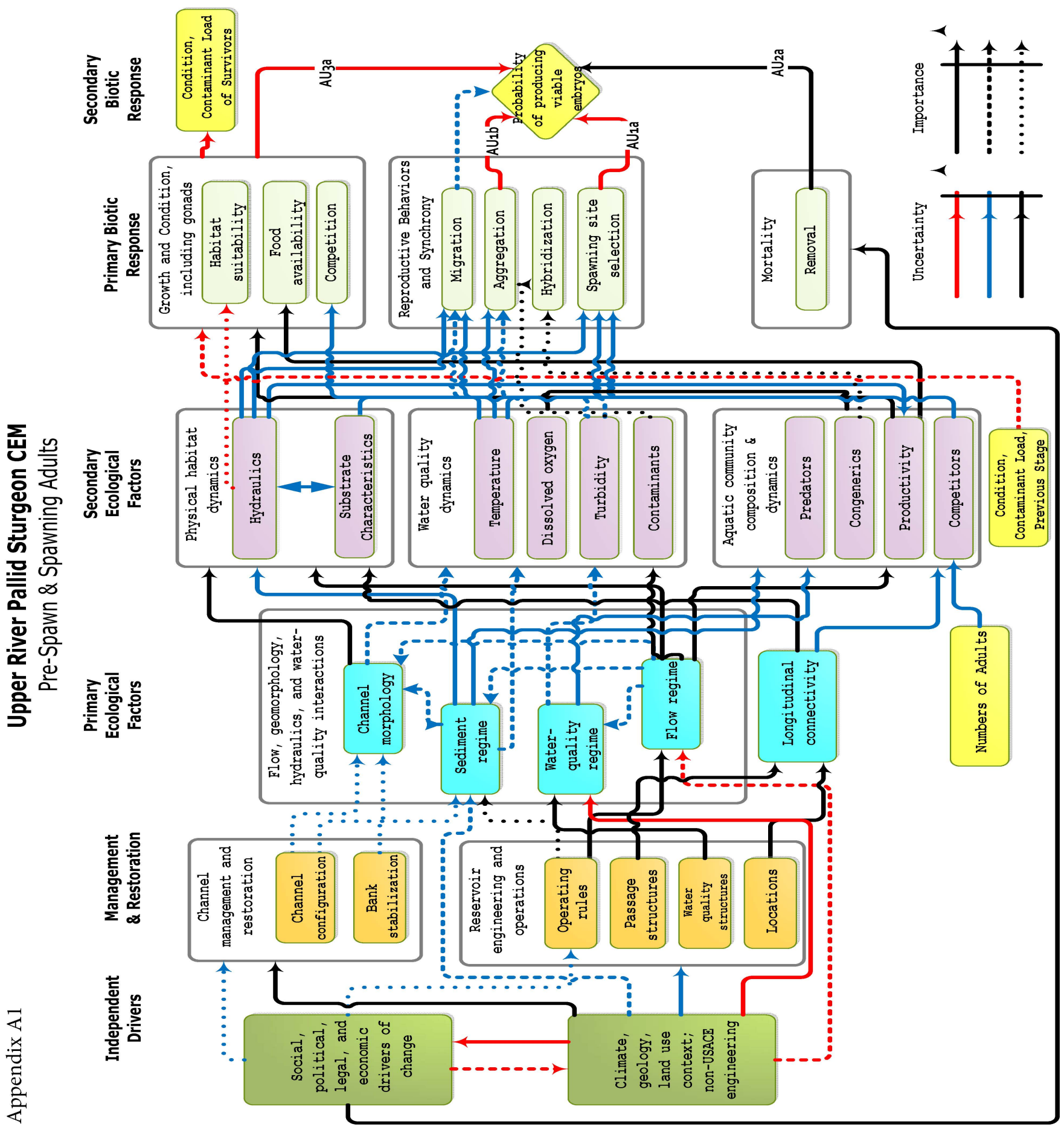




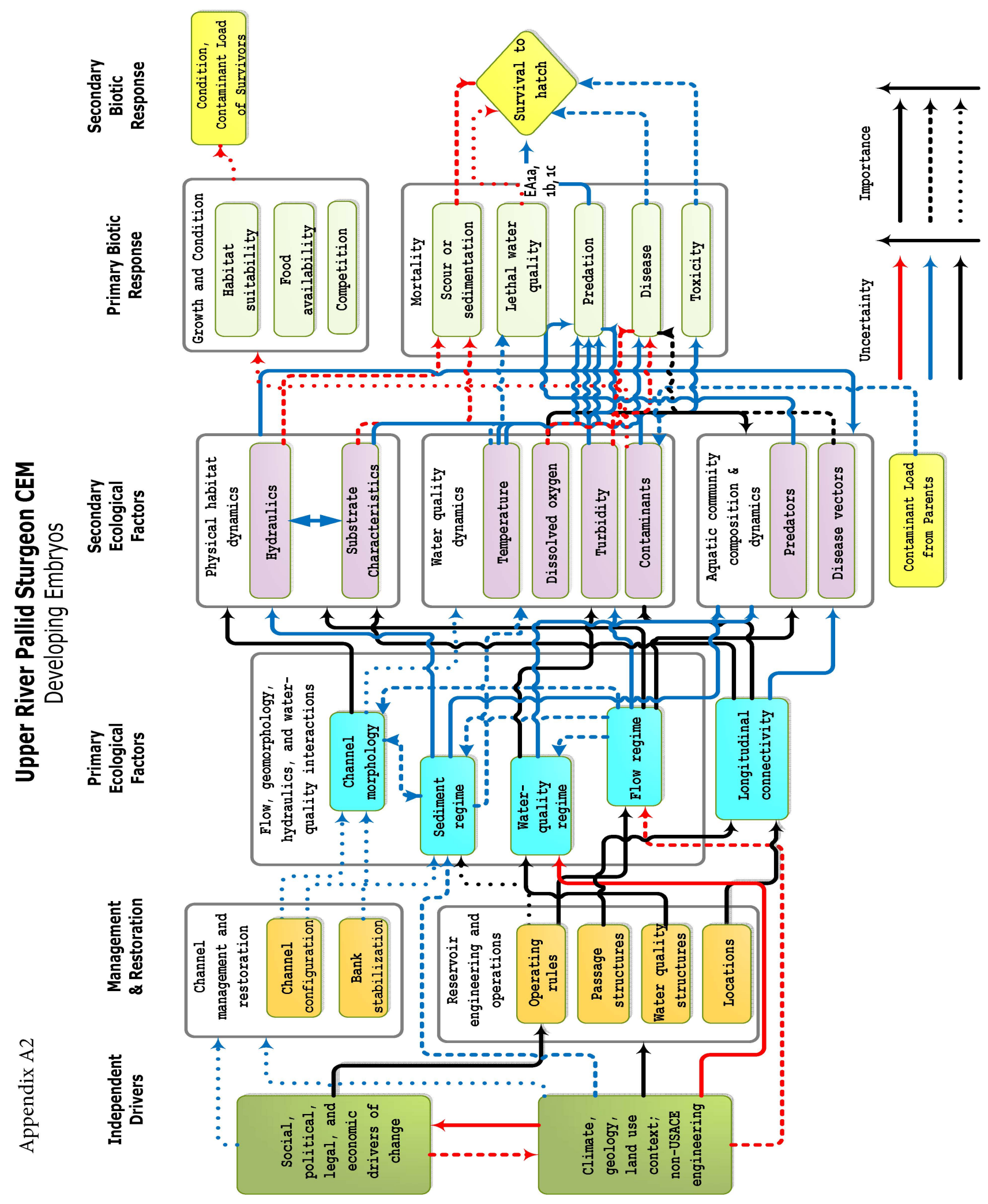




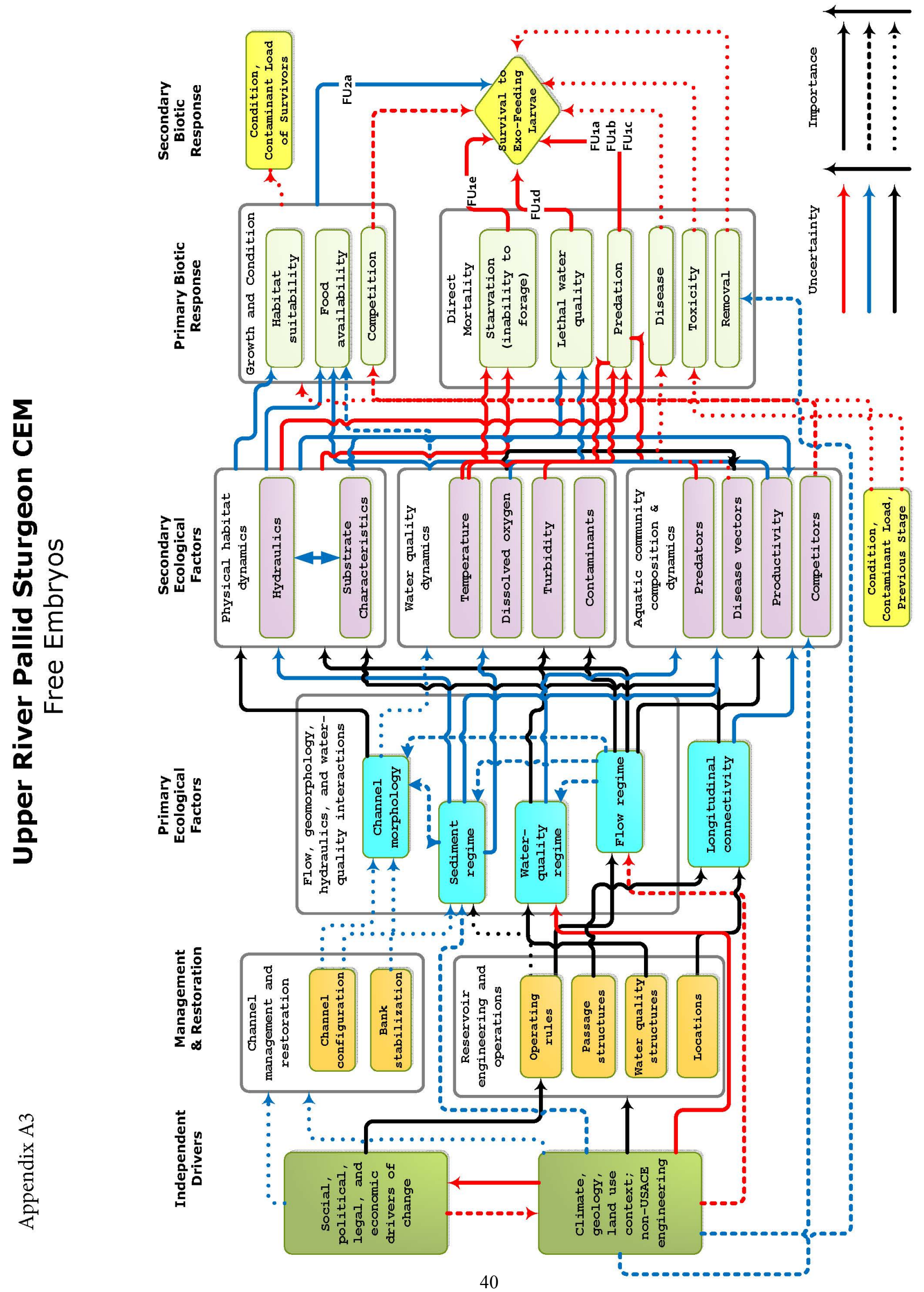




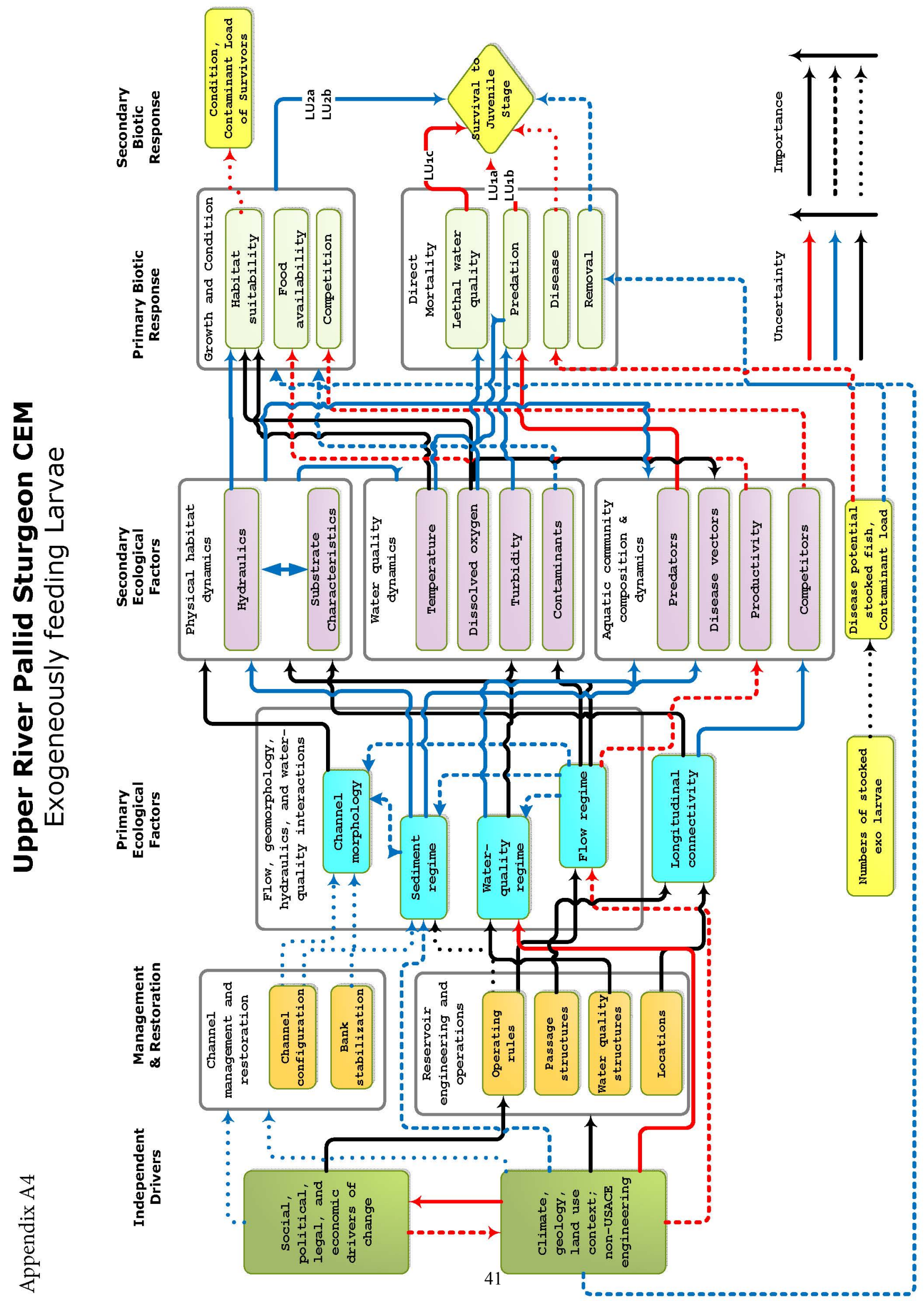




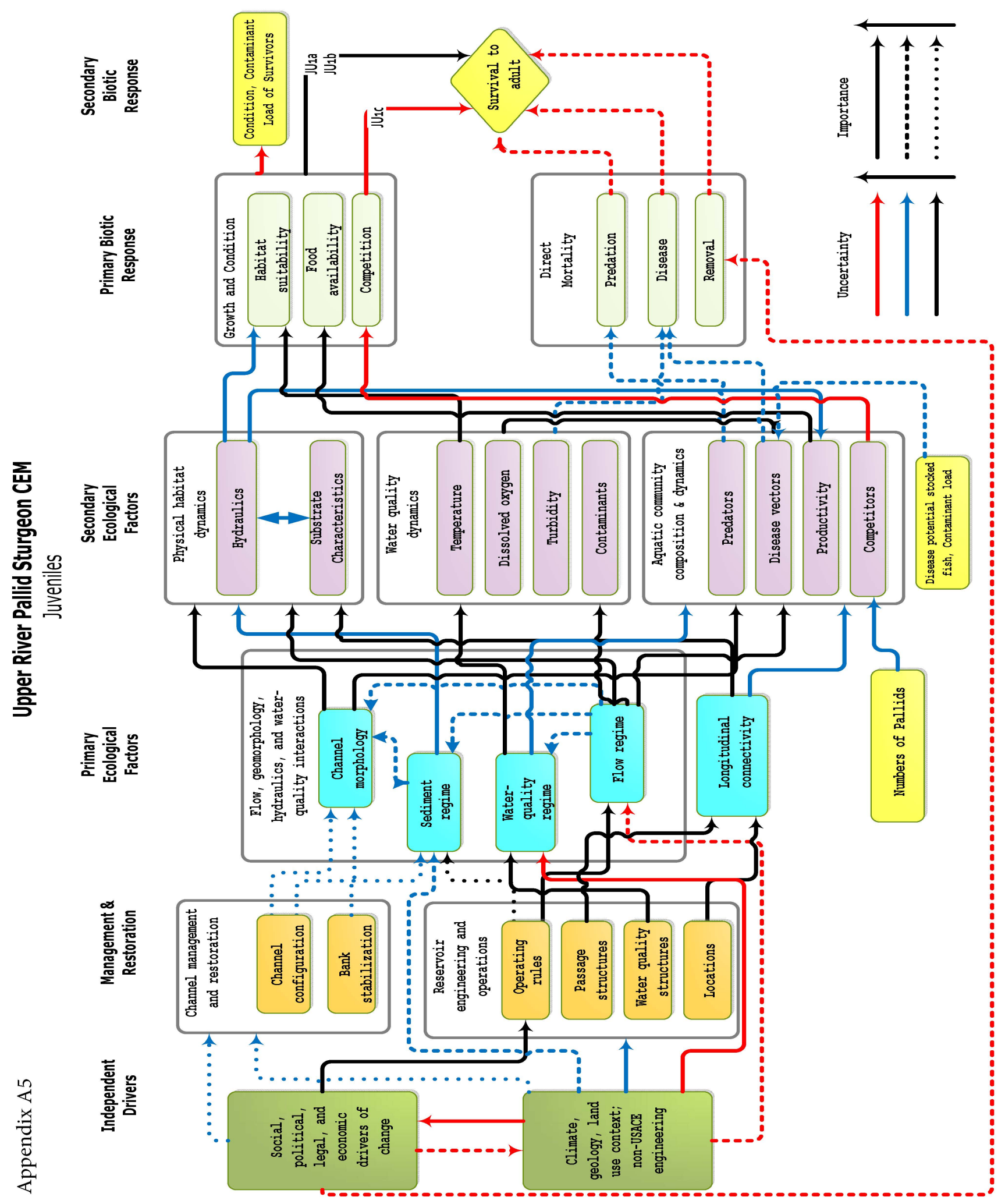




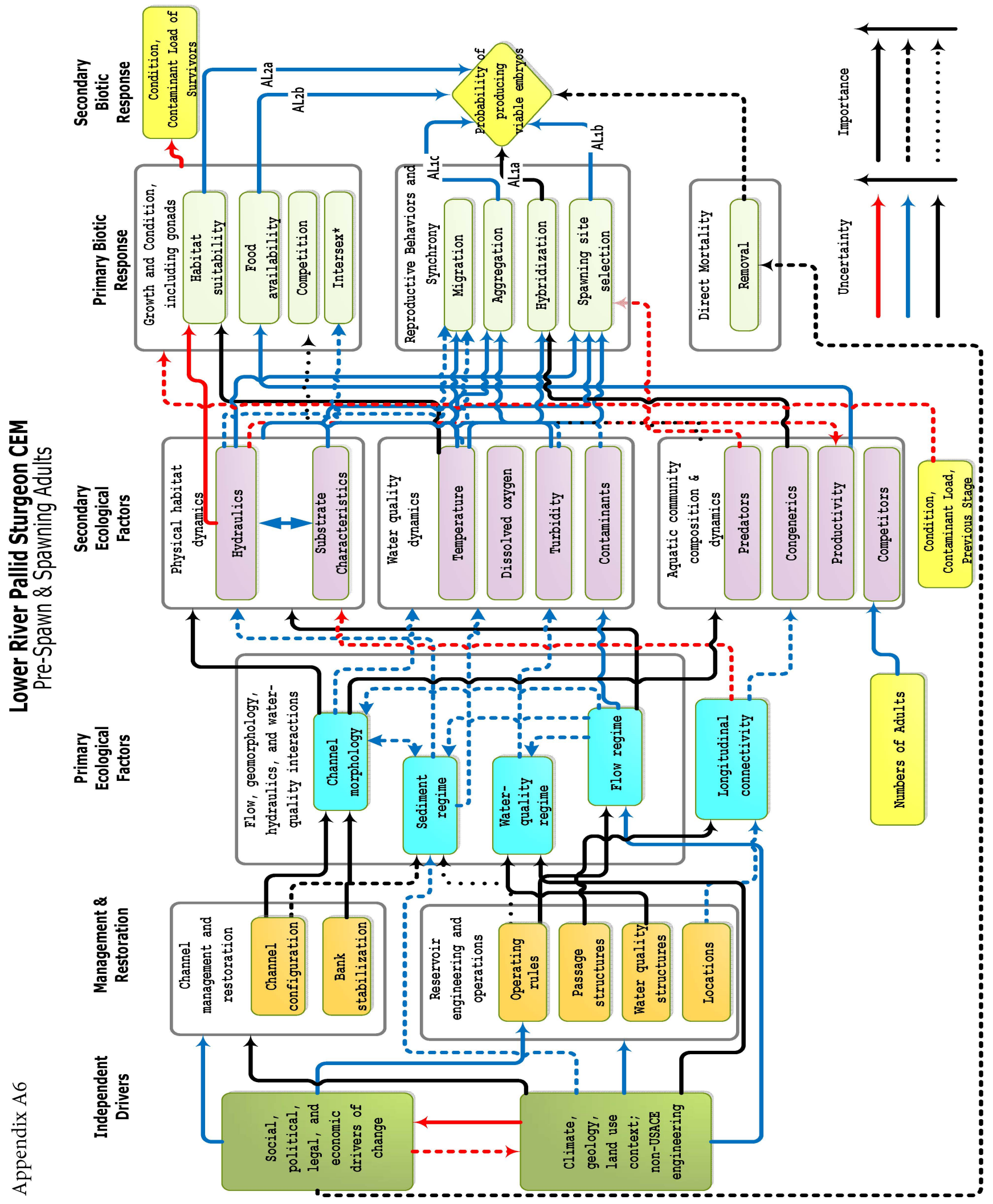




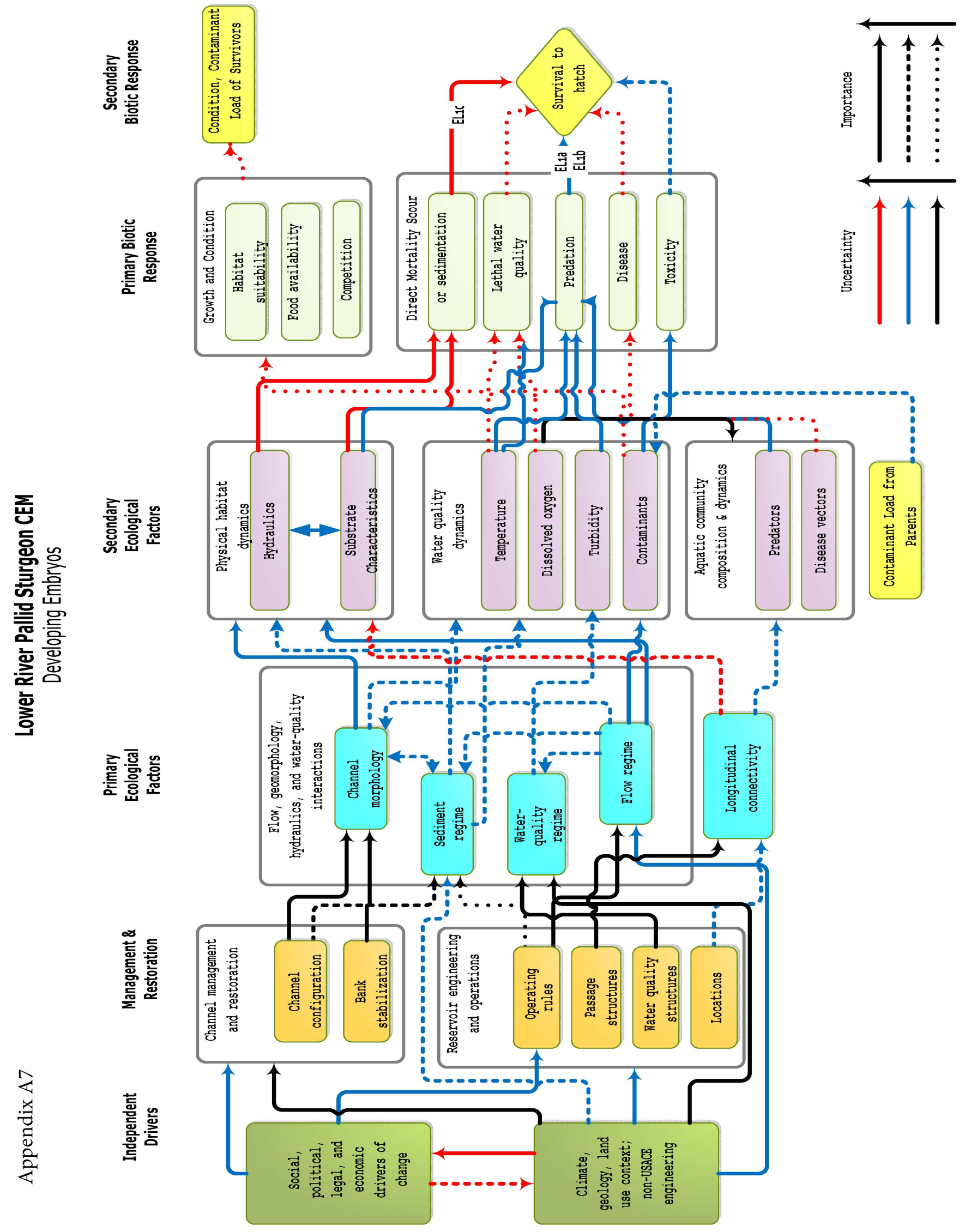




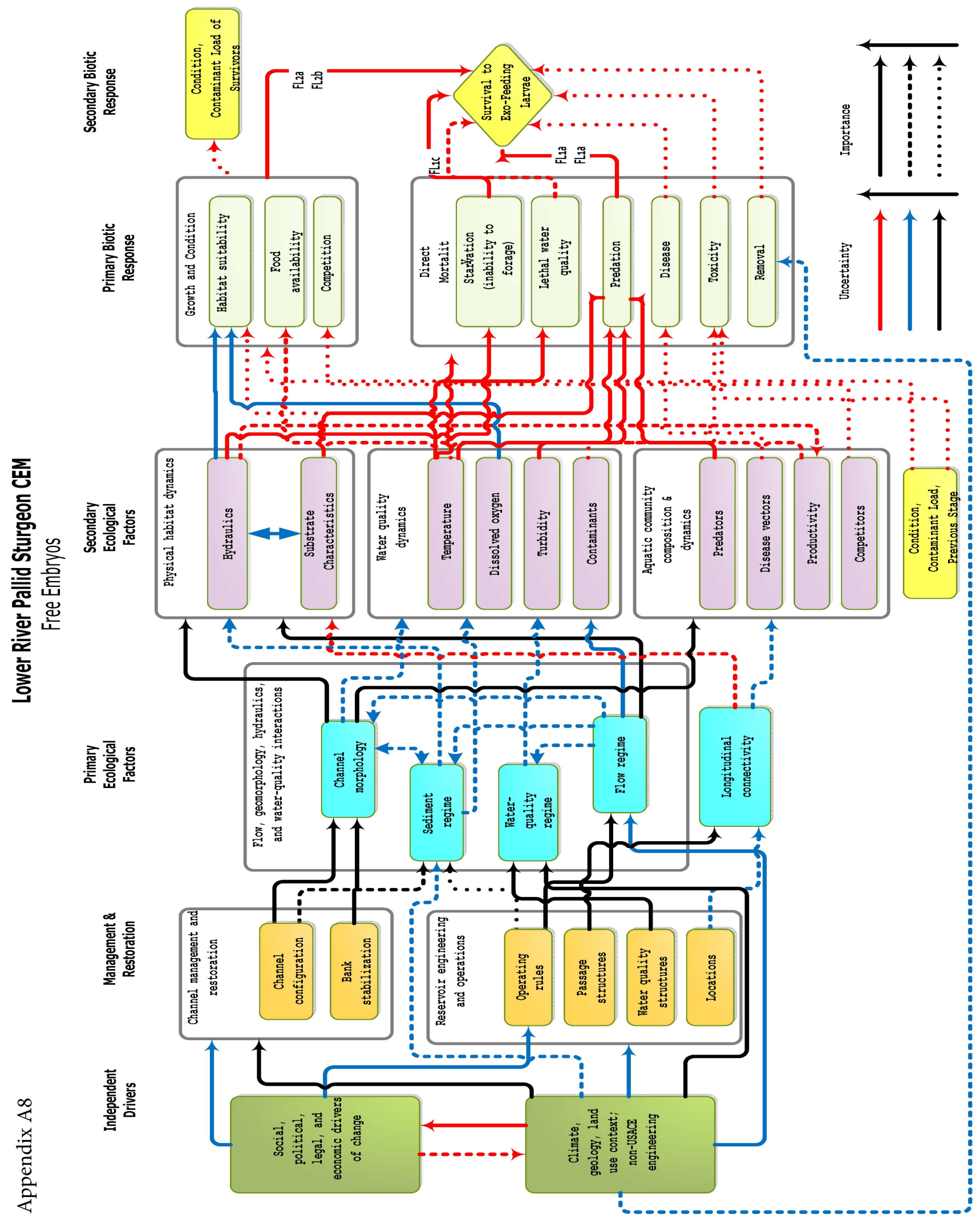




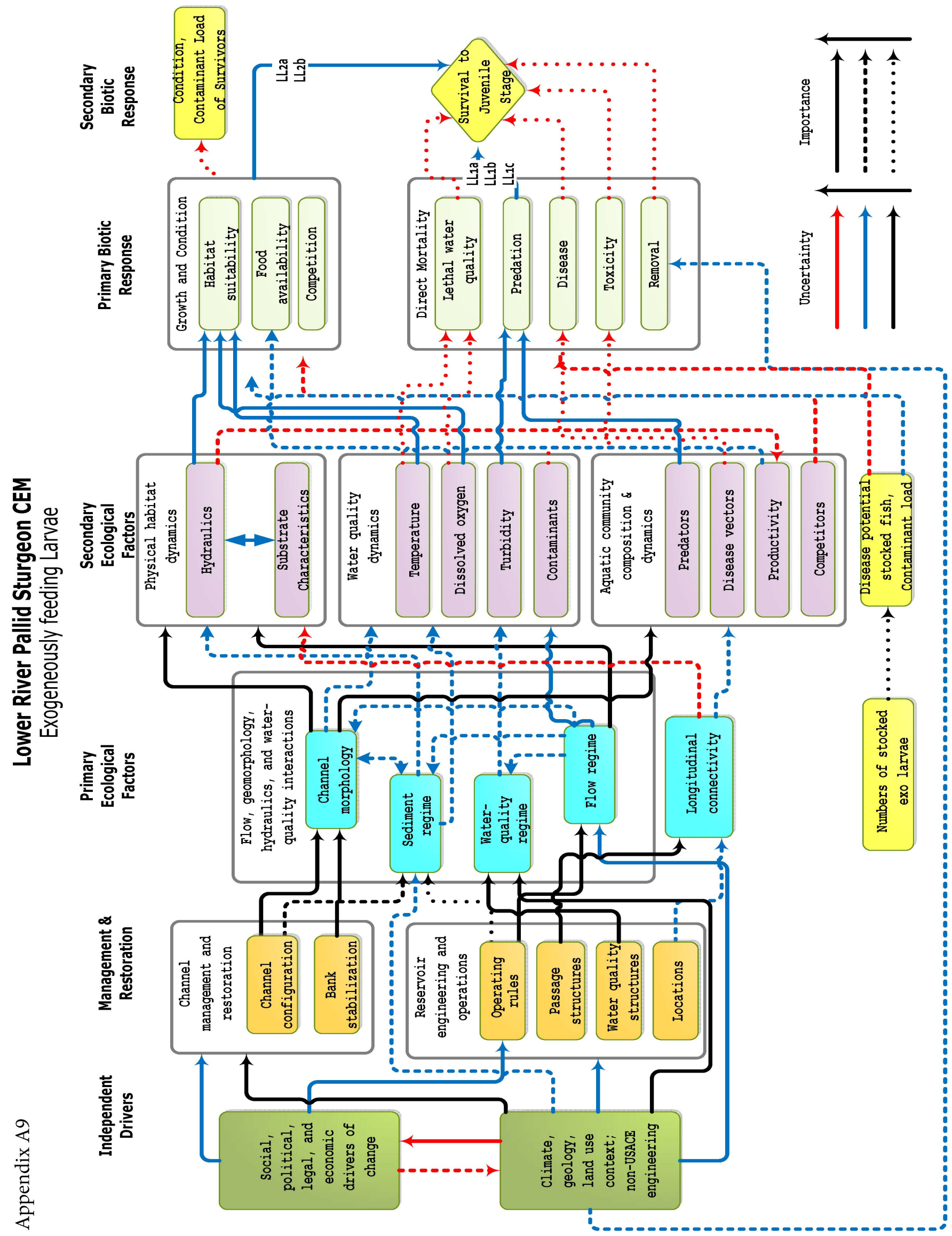




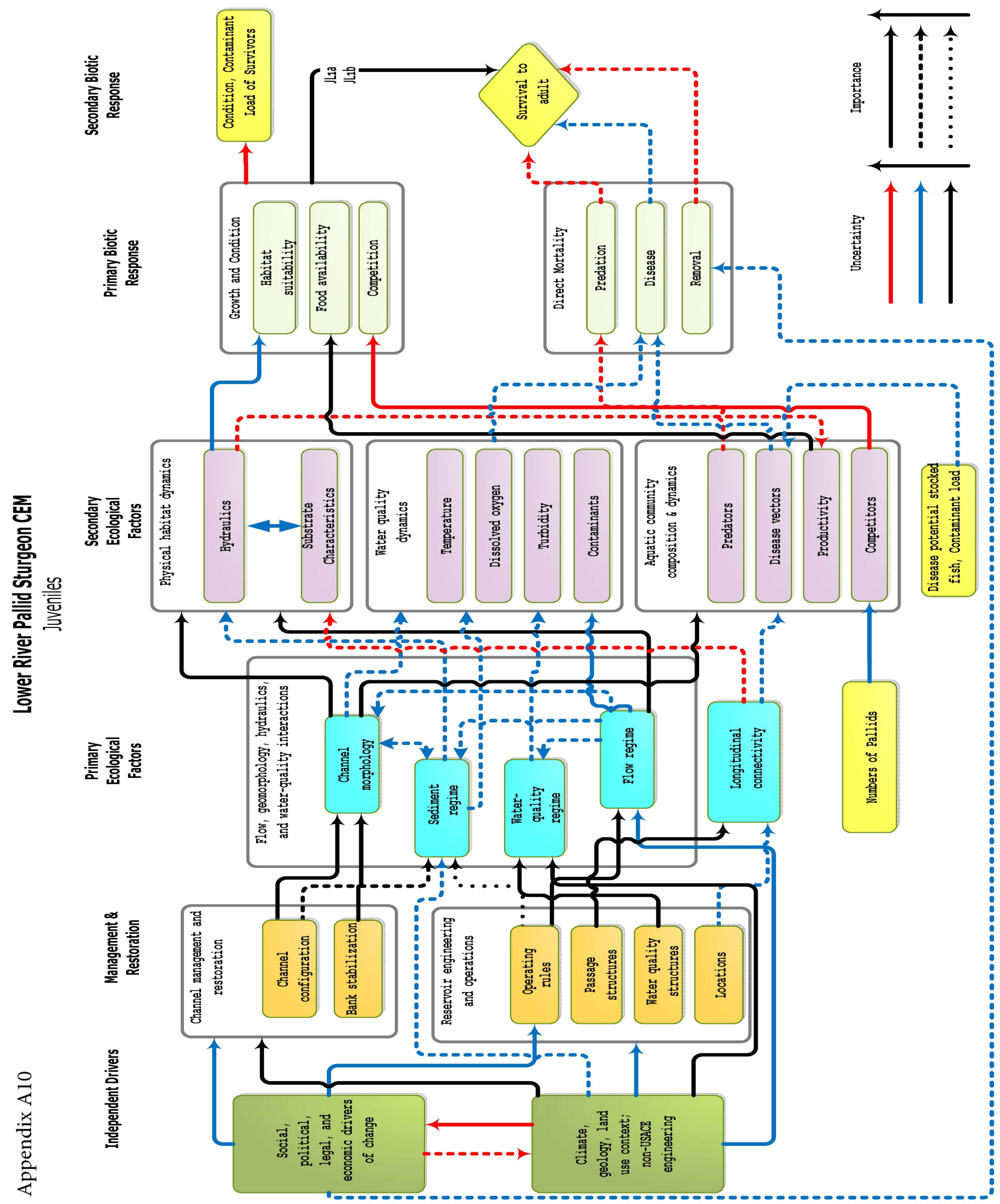

